\title{
Comprehensive Assessment of Local Population Chemical Exposome by Combination of Organic Pollutant- and Metal-Multi-Residue Analysis in Hair
}

\author{
Alba Iglesias-González ${ }^{1,2}$ [D . Charline Schaeffer ${ }^{1}$. Georges Dahm ${ }^{3}$. Emilie M. Hardy ${ }^{1}$. Achilleas Pexaras ${ }^{1}$. \\ Paul Palazzi $^{1}$ - Brice M. R. Appenzeller ${ }^{1}$
}

Received: 22 July 2021 / Revised: 7 October 2021 / Accepted: 29 October 2021 / Published online: 10 November 2021

(c) The Author(s) 2021

\begin{abstract}
Awareness of the adverse effects of exposure to pollutant mixtures, possibly much more severe than individual chemicals, has drawn attention towards the necessity of using multi-residue methods to obtain the most possible comprehensive information on exposome. Among the different biological matrices used for exposure assessment, hair enables to detect the largest number of chemicals, including many classes such as persistent pollutants, hydrophilic metabolites and metals. Most biomonitoring studies are however focused on a limited number of pollutants and only give a partial information on exposure. Combining several multi-residue methods, the present study aimed at assessing the exposure of a population to an extensive variety of chemicals by hair analysis. One hair sample was collected from each participant (55 children and 134 adults). Samples were analysed with three different multi-residue methods, targeting, respectively, 152 organic pollutants (pesticides, PCBs, bisphenols, PBDEs), 62 polycyclic aromatic hydrocarbons (PAHs) and metabolites, nicotine and cotinine and 36 metals. From 33 to 70 organic chemicals were detected in each child's hair sample, and from 34 up to 74 in adults. From 7 to 26 PAH were detected per child, and 7 to 21 in adults. Twenty-three to 27 metals were detected per child and 21 to 28 per adult. The highest median concentration were observed for zinc ( $143 \mu \mathrm{g} / \mathrm{mg}$ in children; $164 \mu \mathrm{g} / \mathrm{mg}$ in adults), bisphenol A (95.9 pg/ $\mathrm{mg}$ in children; $64.7 \mathrm{pg} / \mathrm{mg}$ in adults) and nicotine $(66.4 \mathrm{pg} / \mathrm{mg}$ in children; $51.9 \mathrm{pg} / \mathrm{mg}$ in adults). The present study provides the most comprehensive exposure assessment ever and highlights the simultaneous exposure to multiple classes of pollutants in the general population. The results support the use of multi-residue methods for future studies on exposure-associated effects, to document exposome and better consider the effect of chemical mixtures.
\end{abstract}

Keywords Exposome $\cdot$ Hair analysis $\cdot$ Multi-residue methods $\cdot$ Biomonitoring $\cdot$ Organic pollutants $\cdot$ Metals

\section{Introduction}

The concept of exposome, defined by Wild (2012) as "every exposure to which an individual is subjected from conception to death", has been developed on the ground that human

Alba Iglesias-González

alba.iglesiasgonzalez@lih.lu

1 Human Biomonitoring Research Unit, Department of Population Health, Luxembourg Institute of Health, 1 A-B Rue Thomas Edison, L-1445 Strassen, Luxembourg

2 University of Luxembourg, 2 Avenue de l'Universite, L-4365 Esch-sur-Alzette, Luxembourg

3 Laboratoire National de Santé, 1 Rue Louis Rech, L-3555 Dudelange, Luxembourg was simultaneously exposed to several stressors that could all influence health, acting individually or in combination. Exposure to chemical pollutants is considered an important part of exposome, and a great deal of scientific studies associated various pollutants with different health issues (Global Alliance on Health and Pollution 2019, World Health Organization 2020). Indeed, for the year 2018, pollution was considered responsible for 9 million deaths worldwide, which corresponds to $16 \%$ of the total global deaths, and to $21 \%$ of all deaths from cardiovascular disease, $26 \%$ of deaths due to ischaemic heart disease, $23 \%$ of deaths due to stroke, $51 \%$ of deaths due to chronic obstructive pulmonary disease, and $43 \%$ of deaths due to lung cancer" (Landrigan et al. 2018). Anthropogenic activities are usually considered the main contributors to chemical exposome, with at the forefront industrial activities, transports and agriculture, which are 
responsible for the contamination of human surroundings, water and food, with various chemicals such as metals, persistent organic pollutants, pesticides, flame retardants and polycyclic aromatic hydrocarbons (PAH) among others. As a consequence of this global contamination, the simultaneous exposure to a multitude of chemicals has become almost unavoidable for the general population, and made even more complex the understanding of exposure-induced adverse effects on health. Indeed, an increasing number of studies demonstrated that multiple chemical exposure can lead to different or stronger effects than exposure to each chemical separately, and point out the need of novel approaches allowing more comprehensive exposure assessment (Carlin et al. 2013; Kortenkamp 2014; Silva et al. 2002; Sarigiannis and Hansen 2012; Kostoff et al. 2018; Docea et al. 2019; Tsatsakis et al. 2017).

Nevertheless, most biomonitoring studies only targeted a few number of chemicals and therefore only provided partial information on exposome (Carlin et al. 2013; Braun et al. 2016). Indeed, the simultaneous assessment of exposure to chemicals from different classes remains a significant challenge (Hernández et al. 2017). On the one hand, several different pre-analytical preparations and analytical techniques may be needed to face the various physicochemical specificities of the different compounds. On the other hand, assessing exposure to different chemical classes of pollutants usually require the analysis of different types of specimens (Haines et al. 2017; Vorkamp et al. 2021). As an example, persistent organic pollutants such as organochlorine pesticides and PCBs are usually analysed in plasma with gas chromatography-based method, whereas hydrophilic pesticides, metabolites and phenols are analysed in urine, preferably with liquid chromatography. Concerning metals, for which ICP-MS is the most common technique used nowadays, both urine and blood can often be used, although specific information such as speciation can lead to privilege one matrix or the other. In parallel to fluids, other matrices have gained attention for the analysis of chemical pollutants, and hair in particular appears an interesting candidate to conduct multiresidue analysis. The first studies presenting the detection of metals in hair actually date back to the 50's to 70's and have been followed by a plethora of articles confirming the relevance of metal concentration in hair as a proxy of body content in various contexts such as environmental contamination, occupational exposure, or even to assess micronutrient status (Appenzeller 2015; Li et al. 2011; Protano et al. 2020; Rodrigues et al. 2008; Shah et al. 2011). Concerning organic pollutants, although the first studies only focused on persistent chemicals such as dioxins, PCBs and organochlorine pesticides, hair analysis was further along extended to many other groups of pollutants (Appenzeller and Tsatsakis 2012). Indeed, the most recent studies in the field demonstrated the possibility to detect in hair, pesticides from more than 20 different chemical families (and including hydrophilic compounds and metabolites) (Peng et al. 2020a; Beranger et al. 2018), bisphenols, phthalate and plasticizer metabolites (Peng et al. 2020b; Fays et al. 2021), as well as PAHs and their metabolites (Palazzi et al. 2019, 2018). These studies were conducted on quite significant numbers of subjects and provided the first illustrations of differences in exposome between different populations. Nevertheless, although targeting significant numbers of chemicals, each of these studies was focused on specific groups of pollutants and therefore only provided partial information on the chemicals exposome of the populations under study. Moreover, all were conducted on specific age subgroups (either on adults or on children), which did not allow to investigate different exposome pattern between children and adults from the same area.

The present study was conducted with the aim of obtaining the most comprehensive information possible on the human chemical exposome with biomonitoring approaches. For this purpose, we combined the most up-to-date methodologies developed and validated by our team for the analysis of chemical pollutants in hair. This approach, allowing the analysis of 225 organic chemicals (pollutants and pollutant metabolites from various chemical families) and 36 metals, represents the highest number of biomarkers of exposure simultaneously targeted in hair samples. The methodology was applied to hair samples were collected from 55 children and 134 adults, all living in the same city located in the North region of France. The results were used to explore the local specificities in the chemical exposome compared to other regions, and allowed investigating for the first time the differences in exposure between children and adults living in the same place. 


\section{Material and Methods}

\section{Study Area and Description of the Population}

A total of 189 volunteers, all inhabitants of Grande-Synthe city, including 134 adults and 55 children took part in the present study. The age of the adults ranged from 18 years old to 85 years old. Children age ranged from 1 year old to 16 years old. All the participants were duly informed about the study protocol and objectives and provided an informed consent. The area of Grande-Synthe is an urban region of approximately $21 \mathrm{Km}^{2}$ and 23,634 inhabitants in 2015. This city is located at the north coast of the France, at $51^{\circ} 00^{\prime} 50^{\prime \prime} \mathrm{N}$ $2^{\circ} 18^{\prime} 10^{\prime \prime} \mathrm{E}$ specifically. It belongs to the region of Nord-Pasde-Calais, district of Dunkerque, which is one of the most urbanized regions of France.

\section{Sampling}

Participant inclusion and hair sample collection was conducted on the second semester of 2017. Hair was collected by cutting a lock at the vertex region of the scalp where the hair growing is more homogeneous (Kintz et al. 2015). Then the lock was placed in an aluminium foil, labelled and sent for analysis. A maximum of $9 \mathrm{~cm}$ length, starting from the skin, were used for the chemical analysis. This length was determined based on previous study, where there was not found significant differences in the concentration of chemicals detected in hair segments until $9 \mathrm{~cm}$ (Beranger et al. 2018).

\section{Chemical Analysis}

The selection of the pollutants targeted here was based on studies previously published (Beranger et al. 2020, 2018; Iglesias-González et al. 2020; Peng et al. 2020a; Palazzi et al. 2019, 2018). Overall, about 180 pesticides and/or metabolites were selected a priori, based on: (1) sales data (in tons, for the south-western and north-eastern regions), provided by pesticide suppliers, as required since 2008 (Agriculture 2012); (2) priority pesticides in terms of food safety, based on the probability of exceeding the acceptable daily intake in the general French population (Nougadère et al. 2014); (3) data on domestic uses or indoor environment contamination (air, dust) in France, indexed in a summary by the national observatory of pesticide residues (ORP 2010), completed by an expert assessment based on more recent data; (4) the international expert assessment conducted in 2010 to guide the French biomonitoring strategy (Fillol et al. 2014). The list of polycyclic aromatic hydrocarbons (PAHs) analysed in the hair samples was based on the US-EPA priority list and on previous biomonitoring studies based on hair analysis (Palazzi et al. 2019, 2018). The selection of metals was based on technical feasibility.

Three groups of chemicals were defined according to the analytical methods used. Group 1: pesticides, PBDEs, PCBs and bisphenols. Group 2: PAHs, OH-PAHs, nicotine and cotinine. Group 3: metals. Since all the samples collected during this study did not present a sufficient amount to apply the three methods, priority was given as following: group 1, group 2 and group 3. For the analysis of pesticides, PCBs, PBDEs and bisphenols 157 samples were suitable, 40 from children and 117 from adults. Ninety-seven samples were used for the analysis of PAHs, OH-PAHs, nicotine and cotinine, 33 from children and 64 from adults. For metal analysis 52 samples were suitable, 21 from children and 31 from adults. Thirteen samples ( 8 from children and 5 from adults) did not present sufficient amount for any analysis and were therefore excluded from the study.

\section{Decontamination and Extraction}

Hair samples were washed with three successive baths of (1) SDS (Sodium dodecyl sulphate from Sigma-Aldrich - ReagentPlus*L4509), (2) ultrapure water (MilliporeAFS-8 system) and (3) methanol (Biosolve-Analytical grade) under agitation, following the validated protocol described in Duca et al. (2014). Then, samples were put in a tissue, gently dabbed, and placed under soft air flow to dry.

(1) Pesticides, PCBs, PBDEs and bisphenols: Once the samples were dried, they were placed in a stainless grind jar for pulverization using a ball mill Retsch MM200 at $25 \mathrm{~Hz} .50 \mathrm{mg}$ of hair powder per sample were placed in a $4 \mathrm{ml}$ screw neck glass vials (La-Pha- 
Pack) with $10 \mu \mathrm{l}$ of internal standard solution (stable isotope labelled analogues (Hardy et al., 2015) and $1 \mathrm{ml}$ of a mixture of acetonitrile:water at 80:20 (v/v) (Biosolve-ULC/MS grade) and placed under agitation at $37{ }^{\circ} \mathrm{C}, 350$ spm during $12 \mathrm{~h}$ in a New Brunswick-G25 incubator shaker. The standards were purchased from Dr. Ehrenstorfer, Sigma-Aldrich, Toronto Research Chemicals (Toronto, ON, Canada), Cambridge Isotope laboratories (Tewksbury, MA, USA) and US Biological (Swampscott, MA, USA).

(2) Polycyclic aromatic hydrocarbons, nicotine and cotinine: After drying, a hydrolysis with $1 \mathrm{ml}$ of $1 \mathrm{M}$ $\mathrm{NaOH}$ solution and $20 \mu \mathrm{L}$ of internal standard solution at $40{ }^{\circ} \mathrm{C}$ overnight was done.

(3) Metals: After pulverization, between 20 and $50 \mathrm{mg}$ were placed in a $4 \mathrm{ml}$ screw neck glass vials (La-PhaPack) and sent to the Laboratoire National de Santé (L-3555 Dudelange, Luxembourg) for analysis.

\section{Chemical Analysis: Pesticides, PCBs, PBDEs and Bisphenols (Group 1)}

The methodology followed was validated and fully described in Hardy et al. (2015) and Beranger et al. (2018), and used in previous publications (Beranger et al. 2018; IglesiasGonzález et al. 2020; Peng et al. 2020b, 2020a; Hardy et al. 2021).

The day after extraction samples were centrifuged in a Sigma 4-16 KS during $10 \mathrm{~min}$ at $2800 \mathrm{~g}$. The supernatant was split to perform three different type of analysis.

(1) Pesticides and non-persistent organic pollutants analysed with LC-MS/MS: $200 \mu$ l were used for LC-MS/ MS (liquid chromatography coupled with tandem mass spectrometry) analysis. For that, extracts were evaporated at $37^{\circ} \mathrm{C}$ under soft nitrogen stream flow until dryness, reconstituted in $50 \mu \mathrm{l}$ of acetonitrile:ammonium acetate buffer pH6 (10 mM) 75:25 (v/v) mixture and centrifuged at $18,000 \times \mathrm{g}$. for $7 \mathrm{~min}$ (Centrifuge Sigma 1-16 K). Supernatants were recovered and placed in an injection vial (screw neck vials $2 \mathrm{ml}$, La-Pha-Pack) with micro-insert of $200 \mu \mathrm{l}$ (La-Pha-Pack) for injection on a LC-MS/MS equipment (Waters).

(2) Pesticides and persistent organic pollutants analysed with GC-MS/MS by SPME: $300 \mu \mathrm{l}$ were placed in a $10 \mathrm{ml}$ screw neck glass vial with metal caps (Supelco®) with $7.6 \mathrm{ml}$ of phosphate buffer at $\mathrm{pH} 7(1 \mathrm{M})$ to perform solid-phase micro-extraction (SPME), applied for parent pesticides and other persistent pollutants. The analysis was done on a GC-MS/MS (gas chromatograph equipped with a triple quadrupole mass spectrometer from Agilent Technologies 7000A model).

(3) Pesticides and persistent organic pollutants analysed with GC-MS/MS by liquid injection: $300 \mu$ were used for the analysis of metabolite compounds and some persistent pollutants. The extract was evaporated at $37^{\circ} \mathrm{C}$ under soft nitrogen stream flow, followed by adding $30 \mathrm{mg}$ of potassium carbonate $\left(\mathrm{K}_{2} \mathrm{CO}_{3}\right.$ from MerckACS, ISO analyse 104,928), $1 \mathrm{ml}$ of acetonitrile (Biosolve-ULC/MS grade) and $100 \mathrm{ml}$ of a mix of acetonitrile (Biosolve-ULC/MS grade) and $\operatorname{PFBBr}(2,3,4,5$, 6-pentafluorobenzyl bromide, Sigma-Aldrich-101052) at 75:25 (v/v). The mixture was heated at $80{ }^{\circ} \mathrm{C}$ during $30 \mathrm{~min}$ in a heating chamber (Binder-FD53). The liquid phase was placed in a $6 \mathrm{ml}$ evaporation tube (CorningPYREX ${ }^{\circledR}$ ) for evaporation to dryness. The extract was reconstituted in $200 \mu \mathrm{l}$ of ethyl acetate (Biosolve-AR), transferred to a micro-insert and to safe-lock tubes of $1.5 \mathrm{ml}$ (Eppendorf) and centrifuged at $18,000 \times \mathrm{g}$. for 7 min (Centrifuge Sigma 1-16 K). The supernatant was placed in an injection vial (screw neck vials $2 \mathrm{ml}$, LaPha-Pack) with micro-insert of $200 \mu$ (La-Pha-Pack) and put under evaporation. Extract were reconstituted in $20 \mu \mathrm{l}$ of ethyl acetate (Biosolve-AR) and injected in a GC-MS/MS.

The GC-MS/MS equipment was constituted by a Gas chromatograph equipped with a capillary column, a split/ split-less injector, a NCI source, an oven (Agilent Technologies-7890), an autosampler (Agilent Technologies-CTC Pal) and a shaker-incubator; and by a triple quadrupole mass spectrometer (Agilent Technologies 7000A) and a computer (HP Workstation XW4600, Windows Vista Business).

The LC-MS/MS equipment was constituted by liquid chromatograph (Atlantis, Waters), a pre-column with $2 \mu \mathrm{m}$ filter (Waters), a $2.1 \times 150 \mathrm{~mm}$ column (Acquity UPLC® HSS T3 $1.8 \mu \mathrm{m}$; Waters), a sample manager, a quaternary solvent pump equipped with acetonitrile (Biosolve-ULC/MS grade) and ammonium acetate buffer at pH6 $10 \mathrm{mM}$, working in a gradient mode. The injection volume was $10 \mu \mathrm{l}$; and by a triple quadrupole mass spectrometer Xevo TQS (Waters) and a HP computer with MassLynx software. 


\section{Chemical Analysis: Polycyclic Aromatic Hydrocarbons, Nicotine and Cotinine (Group 2)}

The methodology was already described in previous publications (Palazzi et al. 2018, 2019; Grova et al. 2013).

PAHs and PAH metabolites: The day after the overnight hydrolysis, extracts were neutralized with a hydrochloric acid solution at $2 \mathrm{M}$ and $1 \mathrm{ml}$ of acetate buffer $(0.2 \mathrm{M}, \mathrm{pH}$ 1). A liquid/liquid extraction (LLE) was performed with ethyl acetate and cyclohexane 50/50 (v/v) (Biosolve-dioxins). The organic layer which contained PAHs and PAHs metabolites part was taken for a partial evaporation using a soft nitrogen steam flow at $37^{\circ} \mathrm{C}$ with also an addition of n-heptane (Promochem, picograde) and then, reconstituted in $1 \mathrm{ml}$ cyclohexane (Biosolve-dioxins). The aqueous layer was kept for nicotine and cotinine extraction (details described in the section below). A solid-phase extraction was performed as a purification step on Envi-Chrom P cartridges (Superlclean ${ }^{\circledR}$, Sigma-aldrich), elution was done with $2 \mathrm{ml}$ of cyclohexane/ethyl acetate 50/50 (v/v) (Biosolve-dioxins). Extracts were partially evaporated (in the same conditions as mentioned before) with an addition of $400 \mu$ of water (Biosolve-ULC/MS grade). Then, a second LLE with methanol and cyclohexane (Biosolve-dioxins) was realized to separate PAHs from the metabolites. The aqueous phase with PAHs metabolites was evaporated until dryness followed by a derivatization step using $50 \mu \mathrm{L}$ MtBSTFA (Sigma-aldrich) during $1 \mathrm{~h}$ at $60^{\circ} \mathrm{C}$. The final extract was then injected on the GC-MS/MS (Agilent Technologies 7000A model). The organic phase which contained PAHs went under saponification reaction with potassium hydroxide $7 \%$ during $1 \mathrm{~h}$ at $90{ }^{\circ} \mathrm{C}$. A final LLE was done with ethyl acetate and cyclohexane 50/50 (v/v) (Biosolve-dioxins) and water (Biosolve-ULC/MS grade). The final extracts was concentrated until $50 \mu \mathrm{L}$ with an evaporation step prior to the GC-MS/MS injection.

The GC-MS/MS equipment was equivalent to the previous sections except for the ionization source which was an electrical impact one.

Nicotine and cotinine: A carbonate buffer (2 M, pH 10) was added to the aqueous layer which contained nicotine and cotinine in order to reach $\mathrm{pH} 10$. A double LLE with $2 \mathrm{ml}$ of ethyl acetate was done. The organic layer was evaporated to dryness (in the same conditions as mentioned before) and reconstituted with $250 \mu \mathrm{L}$ of acetonitrile/ammonium acetate buffer $10 \mathrm{mM}$ pH6 25:75 (v/v) which was placed on the LC-MS/MS equipment (Waters).

The LC-MS/MS equipment was equivalent to the previous sections except for the column which was a $2.1 \times 100 \mathrm{~mm}$ column (Acquity UPLC® HSS T3 $1.8 \mu \mathrm{m}$; Waters).

\section{Chemical Analysis: Metals (Group 3)}

Metal concentrations were determined using ICP/MS (inductively coupled plasma mass spectrometry). The EN 13,805:2014 (CEN 2019) method was adapted for metal determination. To $20-40 \mathrm{mg}$ of hair powder was placed in a polytetrafluoroethylene (PTFE) vessel with $4 \mathrm{~mL}$ of nitric acid $\left(\mathrm{HNO}_{3}\right)(65 \%), 1 \mathrm{~mL}$ of hydrogen peroxide $\left(\mathrm{H}_{2} \mathrm{O}_{2}\right)$ $(31 \%)$ and $1 \mathrm{~mL}$ of water $\left(\mathrm{H}_{2} \mathrm{O}\right)$. The mixture was left to react for $5 \mathrm{~min}$ at room temperature and then heated over 30 min gradient to $180{ }^{\circ} \mathrm{C}$ by a Mars 5 Xpress microwave (CEM Cooperation). This temperature was maintained over other $30 \mathrm{~min} .1 \mathrm{~mL}$ of the solution obtained was diluted with $9 \mathrm{~mL}$ of internal standard (10 ppb of terbium (Tb), yttrium $(\mathrm{Y})$ and scandium $(\mathrm{Sc})$ in $5 \% \mathrm{HNO}_{3}$ ). Metal analyses were carried out in duplicate on an Agilent $7700 \times$ ICP-MS (Agilent Technologies, Waldbronn, Germany) in helium (He) collision cell modus and using external calibration $(0 \mu \mathrm{g} / \mathrm{L}-1000 \mu \mathrm{g} / \mathrm{L})$.

\section{Quality Controls, Limit of Detection and Validation Parameters}

Quality controls were added in the different analytical runs of the different groups of biomarkers. Regarding group 1, in each analytical run, nine different quality controls were analysed along with the samples. The quality controls consisted in one blank matrix and eight controls supplemented at different concentrations: $0.5,1,2,5,10,20,50,100 \mathrm{pg} /$ mg. For group 2, in each analytical run, twelve different quality controls were analysed along with the samples. The quality controls included three solvent blanks, one blank matrix and eight controls supplemented at different concentrations: $0.1,0.2,0.5,1,2,10,50,100 \mathrm{pg} / \mathrm{mg}$. The solvent blanks were only included in group 2 to determine the traces of polycyclic aromatic hydrocarbons that could be present in the solvents used for extraction. For group 3, 2 samples 


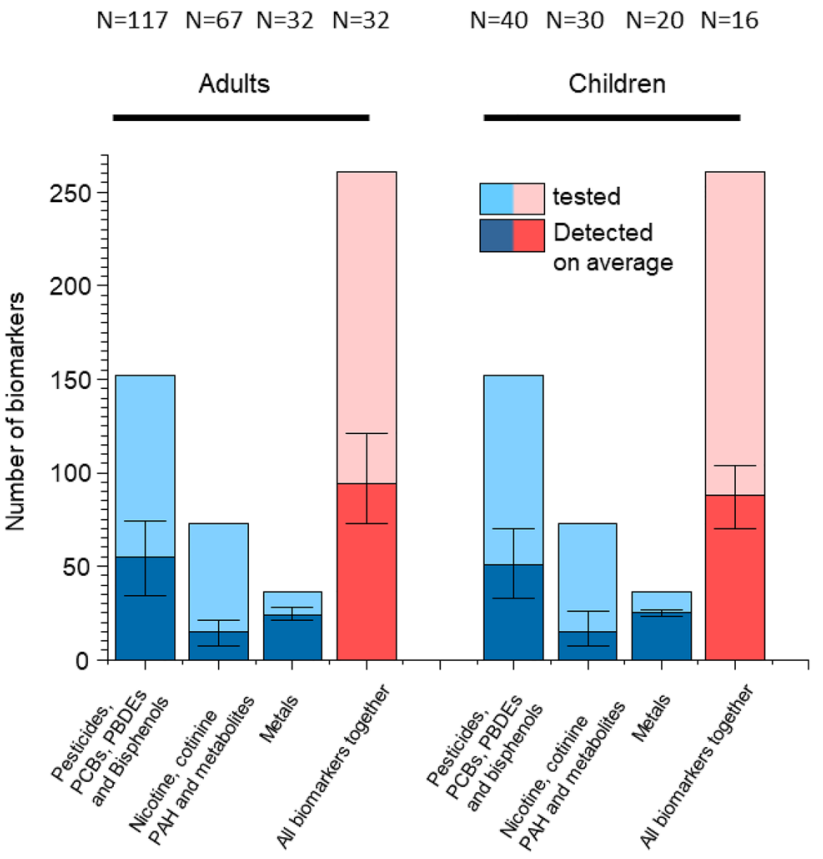

Fig. 1 Number of biomarkers tested (bright) and detected (dark) for each analytical group (blue) and for the sum of the biomarkers tested (pink) in this study in children and adults' hair. Brackets represent the lowest and the highest number of biomarkers detected per sample

of certified reference material (CRM - National Institute for Environmental studies, Japan) were analysed within each run (beginning and end).

The limits of detection (LODs) were defined as the minimum value detected in the present study, for each biomarker, according to the approached used in previous studies (Beranger et al. 2018; Iglesias-González et al. 2020; Palazzi et al. 2018; Peng et al. 2020a). Other validation parameters (limits of quantification, accuracies, variabilities and recoveries) were fully detailed in previous articles: Beranger et al. (2018), Peng et al. (2020b), Hardy et al. (2015), Palazzi et al. (2018), Grova et al. (2013).

\section{Statistical Analysis}

The raw data were used for the calculation of percentage of positive detection, percentiles, minimum and maximum values. These calculations were done on Microsoft Excel version 2013. Spearman and Pearson correlations, $t$-test and z-test were done using Systat Software, Inc. Sigma Plot for Windows version 12.5. For correlations and t-test only the biomarkers detected $\geq 70 \%$ were used. Values under the LOD were substituted by LOD/2. PCA analysis were conducted using RStudio version 1.1 .1463 . Only biomarkers detected $\geq 90 \%$ in each area and $\geq 50 \%$ in total (all areas together) were used. Values lower than the LOD were substituted by 0 and then, the concentration values +1 were $\log$ transformed.

\section{Results}

\section{Biomarkers Detection Frequency and Concentration}

\section{Pesticides, PCBs, PBDEs and Bisphenols}

All the individuals tested positive to several pollutants. Overall, the number of biomarkers detected per children ranged from 33 up to $70($ mean $=51)$ and from 34 up to 74 in adults (mean $=55$ ) (Fig. 1). In children, 24 biomarkers were detected in more than $90 \%$ of the samples, and 15 were detected in all of them (Table 1). The highest median concentrations were observed for bisphenol A: $95.9 \mathrm{pg} / \mathrm{mg}$, p-nitrophenol (PNP): $16.1 \mathrm{pg} / \mathrm{mg}$, bisphenol S: $12.2 \mathrm{pg} / \mathrm{mg}$. In adults, 24 biomarkers were detected in more than $90 \%$ and 12 were detected in all of them. The highest median concentrations were also observed for bisphenol A: $64.7 \mathrm{pg} /$ mg, PNP: 17.9 pg/mg, bisphenol S: 9.59 pg/mg. The highest concentration was observed in children for bisphenol $\mathrm{S}$ $(6387 \mathrm{pg} / \mathrm{mg})$ and in adults for bisphenol A $(11,225 \mathrm{pg} / \mathrm{mg})$, respectively. Nine biomarkers (in children) and 10 (in adults) were detected in 75 to $90 \%$ of the samples. Eleven biomarkers (in children) and 18 (in adults) were detected in 50 to $75 \%$ of the samples. Seventy-two compounds (in children) and 84 (in adults) were detected in $50 \%$ or less. Finally, 12 biomarkers were not detected in any of the samples analysed.

\section{Nicotine, Cotinine and Polycyclic Aromatic Hydrocarbons}

Nicotine was detected in $80 \%$ of the children (median concentration $=66.4 \mathrm{pg} / \mathrm{mg}$ ) and in $73 \%$ of the adults (median $=51.9 \mathrm{pg} / \mathrm{mg}$ ) (Table 2). Cotinine was detected in $96 \%$ of the children (median $=3.59 \mathrm{pg} / \mathrm{mg}$ ) and in $97 \%$ of the adults (median $=3.19 \mathrm{pg} / \mathrm{mg}$ ).

Regarding parent PAHs and their metabolites, from 5 up to 24 (mean $=13)$ compounds were detected in children, and from 5 up to $19($ mean $=13)$ in adults (Fig. 1). 


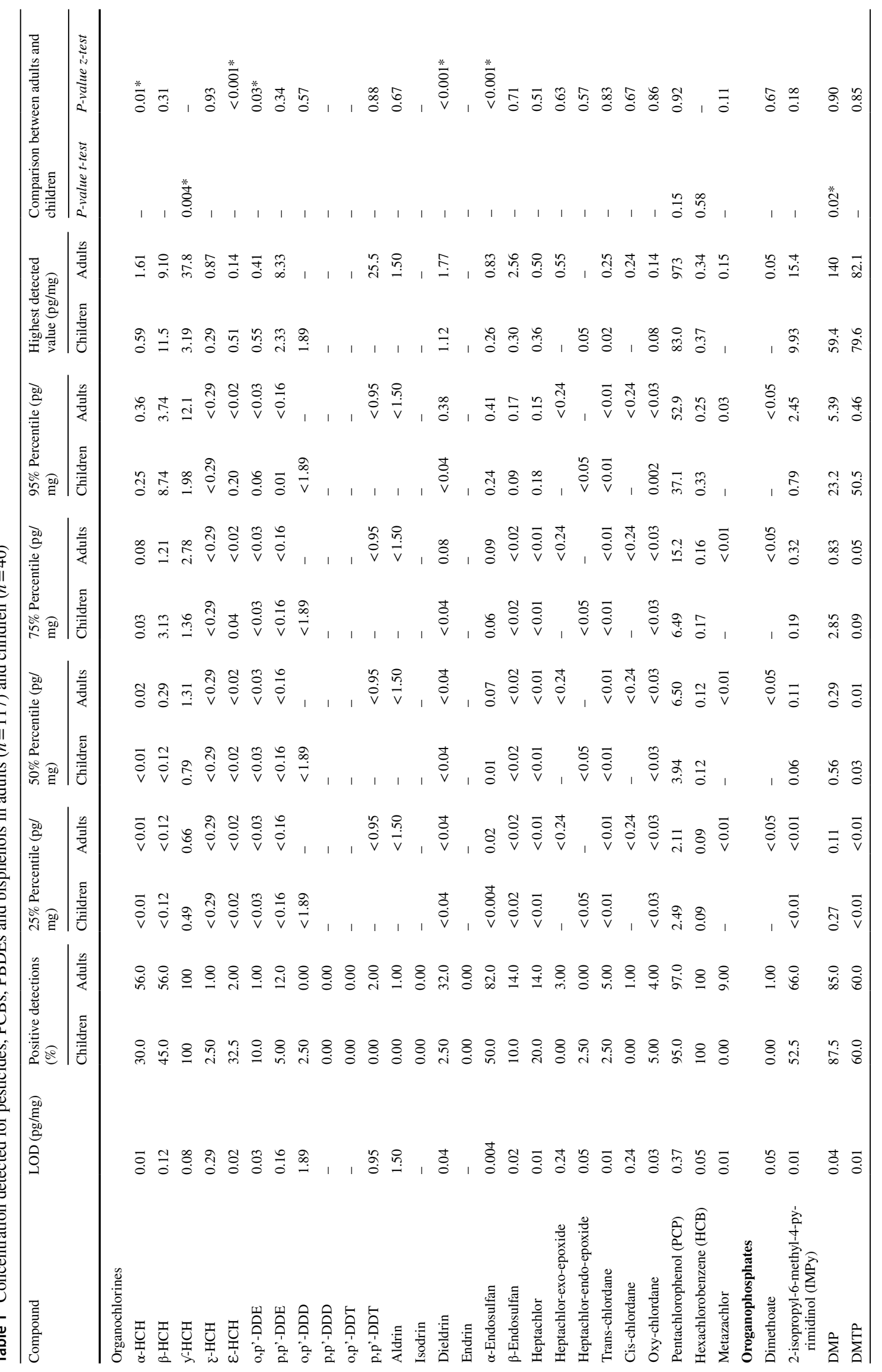




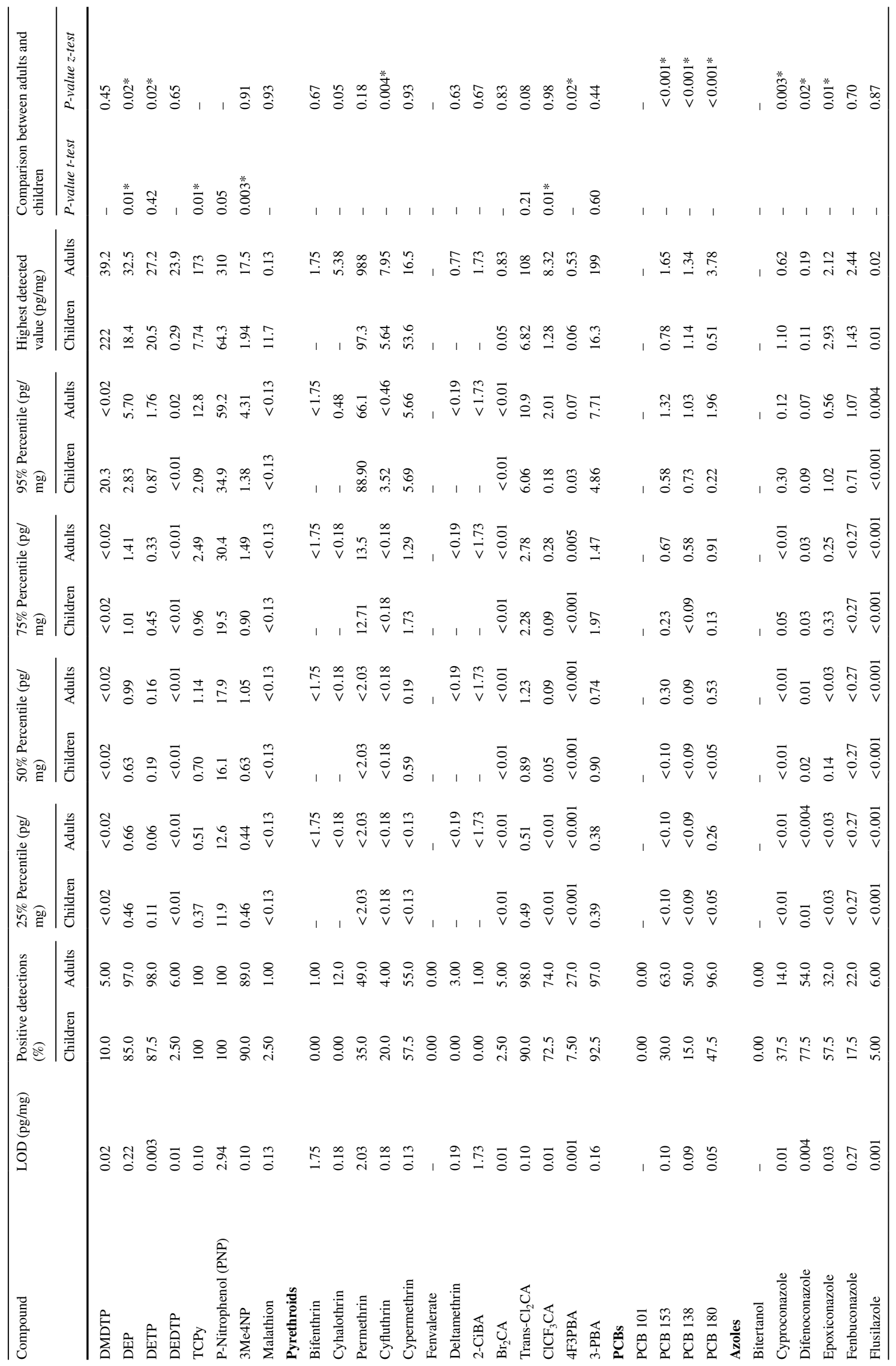




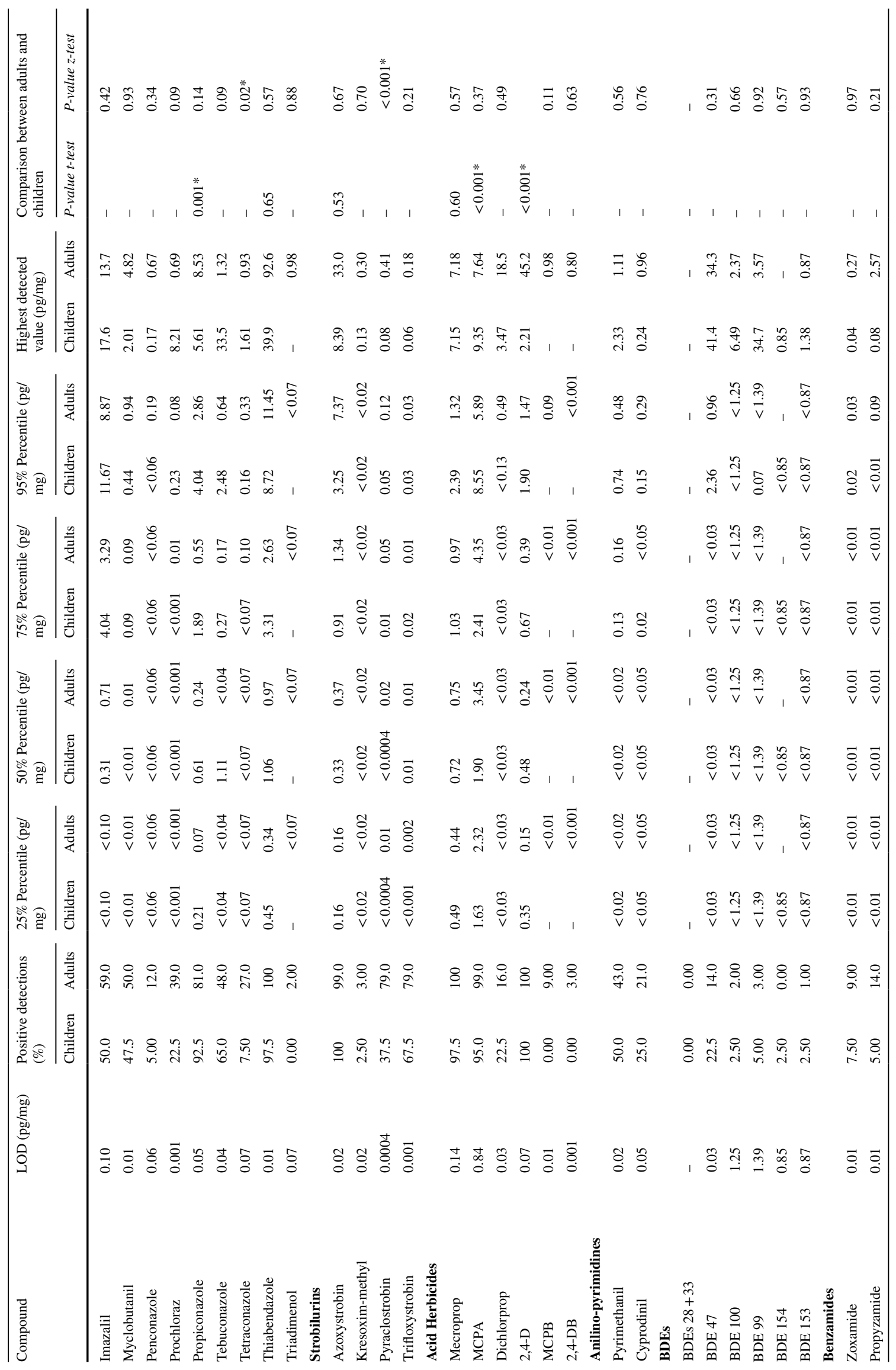




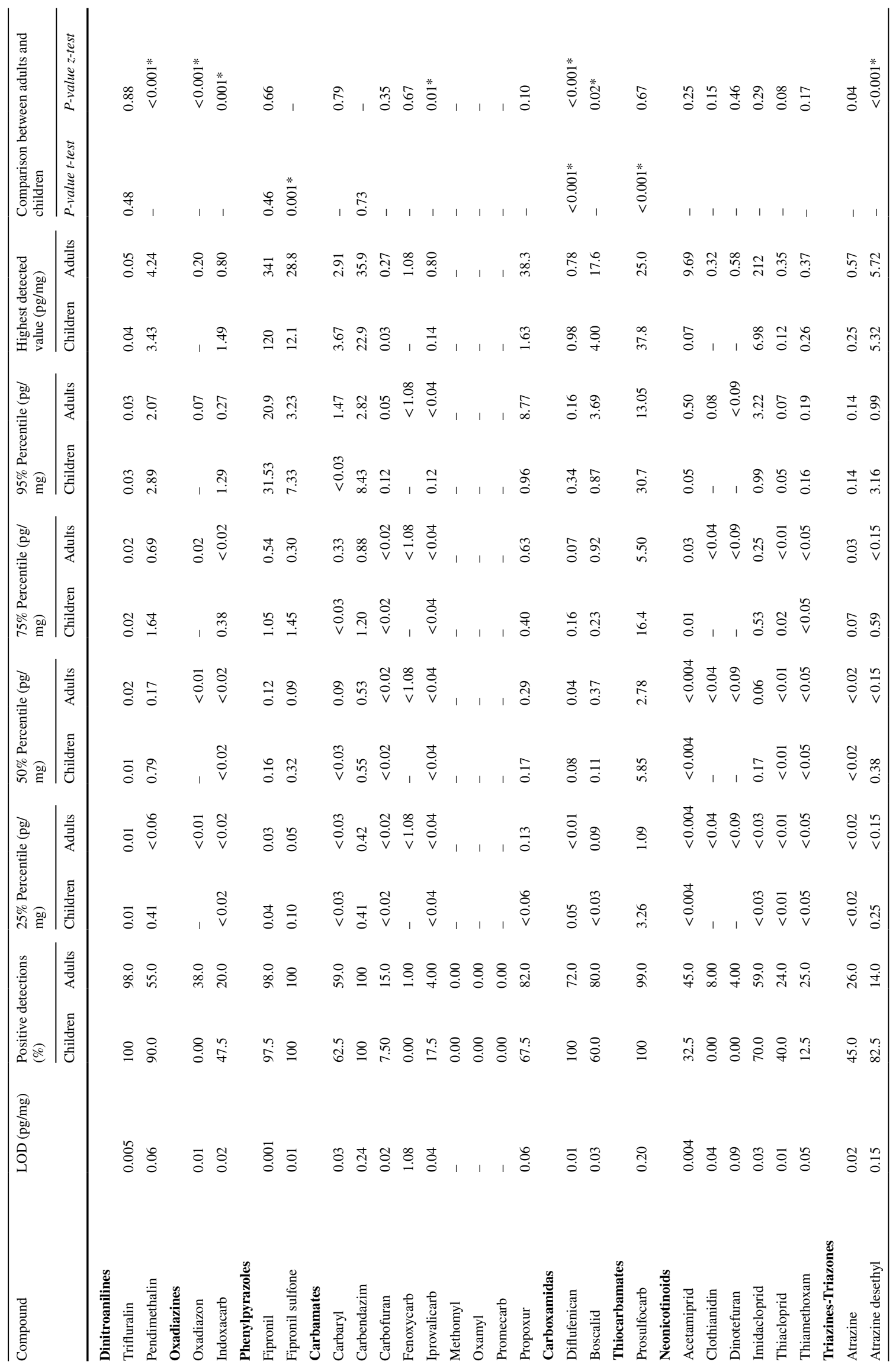




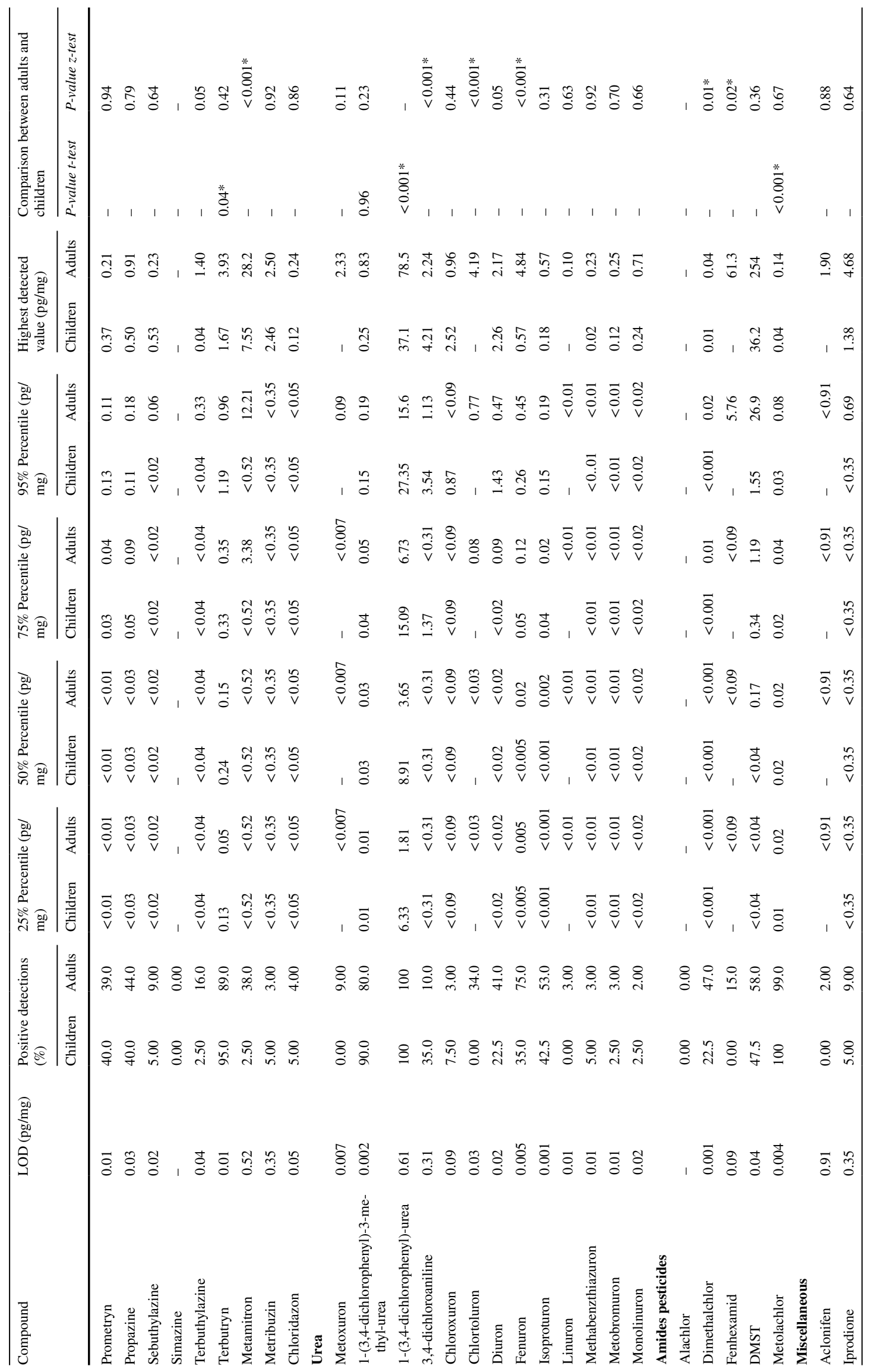




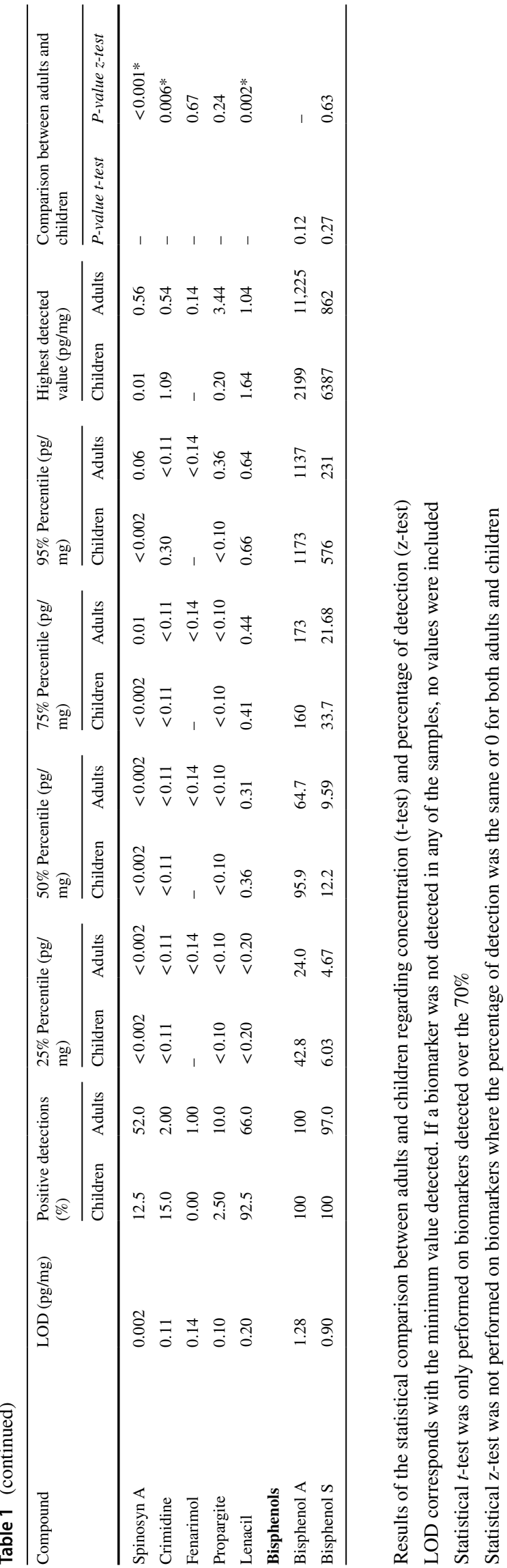

Four parent $\mathrm{PAH}$ were detected in $\geq 75 \%$ of the children: chrysene $($ median $=1.31 \mathrm{pg} / \mathrm{mg})$, benzo $(\mathrm{k})$ fluoranthene $($ median $=0.45 \mathrm{pg} / \mathrm{mg}$ ), benz [a]anthracene (median $=0.32 \mathrm{pg} / \mathrm{mg}$ ) and benzo(ghi)perylene (median $=0.28 \mathrm{pg} / \mathrm{mg}$ ). In adults, 3 compounds were detected in $\geq 75 \%$ : indeno[1,2,3-cd]pyrene ( median $=0.58 \mathrm{pg} / \mathrm{mg}$ ), chrysene $($ median $=0.45 \mathrm{pg} / \mathrm{mg}$ ) and benzo(k)fluoranthene (median $=0.23 \mathrm{pg} / \mathrm{mg}$ ). Two biomarkers were detected in $70 \%$ to $50 \%$ of both children and adults. Six biomarkers (in children) and 8 (in adults) were detected in less than $50 \%$ of the samples. Two parent $\mathrm{PAH}$ were never detected.

Regarding PAH metabolites, 1-OH-Naphthalene (children's median $=0.64 \mathrm{pg} / \mathrm{mg}$, adults' median $=0.83 \mathrm{pg} / \mathrm{mg}$ ) and 2-OH-Naphthalene (children's median $=8.41 \mathrm{pg} / \mathrm{mg}$, adults' median $=6.63 \mathrm{pg} / \mathrm{mg}$ ) were detected in all the samples. These metabolites presented also the highest concentrations: $57.4 \mathrm{pg} / \mathrm{mg}$ for 2-OH-Naphthalene in children and $119 \mathrm{pg} / \mathrm{mg}$ for $1-\mathrm{OH}-\mathrm{Naphthalene}$ in adults. Five metabolites (in children) and 4 (in adults) were detected in $>75 \%$ of the samples. Sixteen biomarkers (in children) and 13 (in adults) were detected in less than $75 \%$ of the samples. Finally, 23 metabolites were not detected in any of the samples.

\section{Metals}

The number of metals detected in children's hair ranged from 23 up to 27 per sample $($ mean $=25)$ and from 21 up to 28 in adult (mean $=24$ ) (Fig. 1). The maximum detected concentration was observed for aluminium: $1450 \mu \mathrm{g} / \mathrm{mg}$ in children and $641 \mu \mathrm{g} / \mathrm{mg}$ in adults (Table 3 ). Internal laboratory tests did not show any enrichment in the aluminium concentration in hair due to storage in aluminium foil (data not shown). Twenty-one metals were detected in all the children with median concentrations ranging from $0.03 \mu \mathrm{g} / \mathrm{mg}$ (antimony) up to $92.5 \mu \mathrm{g} / \mathrm{mg}$ (Iron). In adults, 20 metals were detected in all the samples with median concentrations ranging from $0.05 \mu \mathrm{g} / \mathrm{mg}$ (zirconium and vanadium) up to $164 \mu \mathrm{g} / \mathrm{mg}$ (zinc). Only cobalt was detected in more than $75 \%$ of children (median $=0.04 \mu \mathrm{g} / \mathrm{mg}$ ) and adults (median $=0.10 \mu \mathrm{g} / \mathrm{mg}$ ). Four metals (in children) and 2 (in adults) were detected in $50 \%$ to $75 \%$ of the samples. Two metals (in children) and 8 (in adults) were detected in less than $50 \%$ of the samples. Five metals were not detected in any of the samples.

\section{Exposure Association with Age}

(1) Among the 30 biomarkers of group 1 (pesticides, PCBs, PBDEs and bisphenols) detected in $>70 \%$ of the samples, 15 showed significantly different concentrations between adults and children (Table 1). Eight of these 


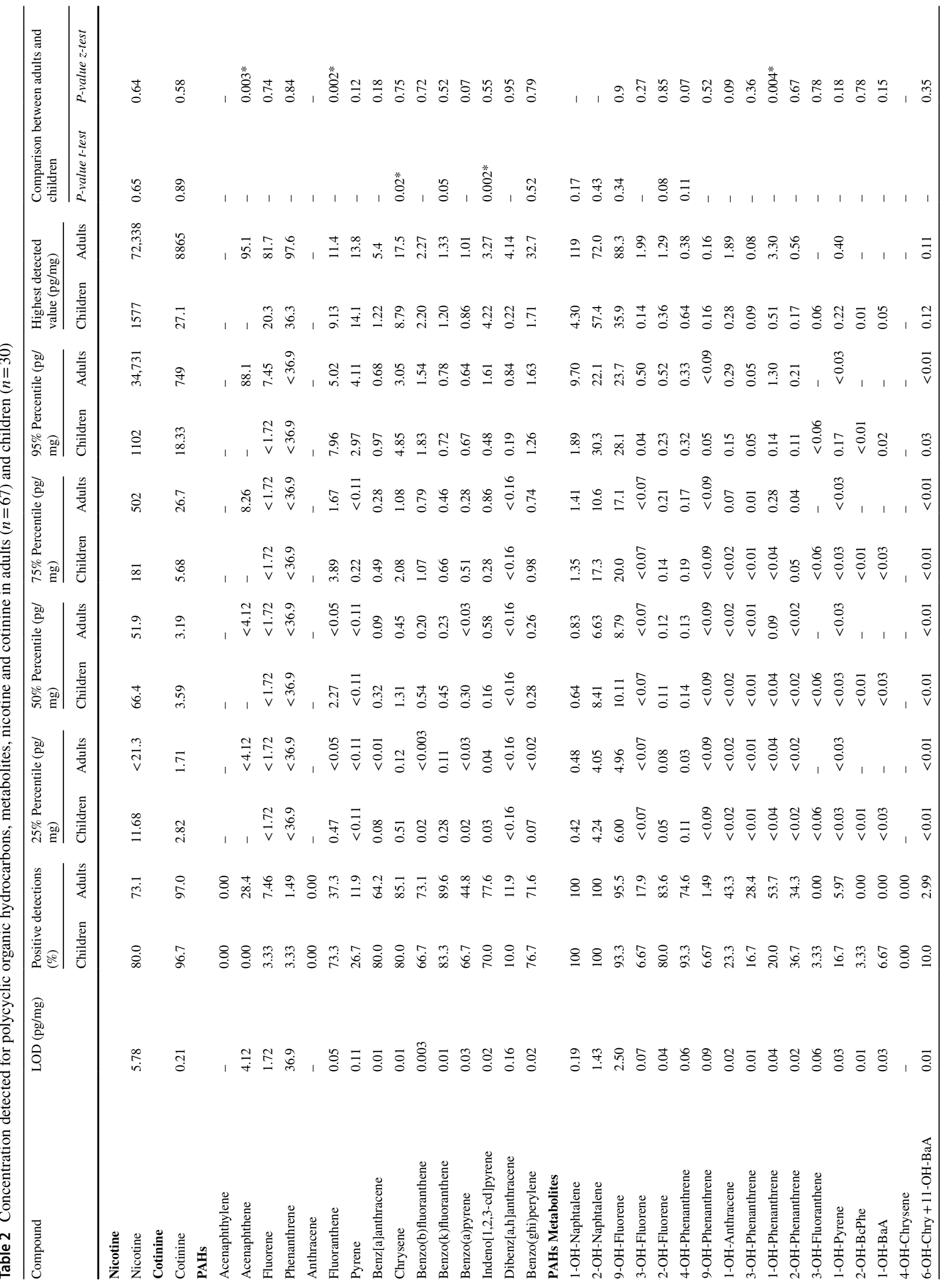




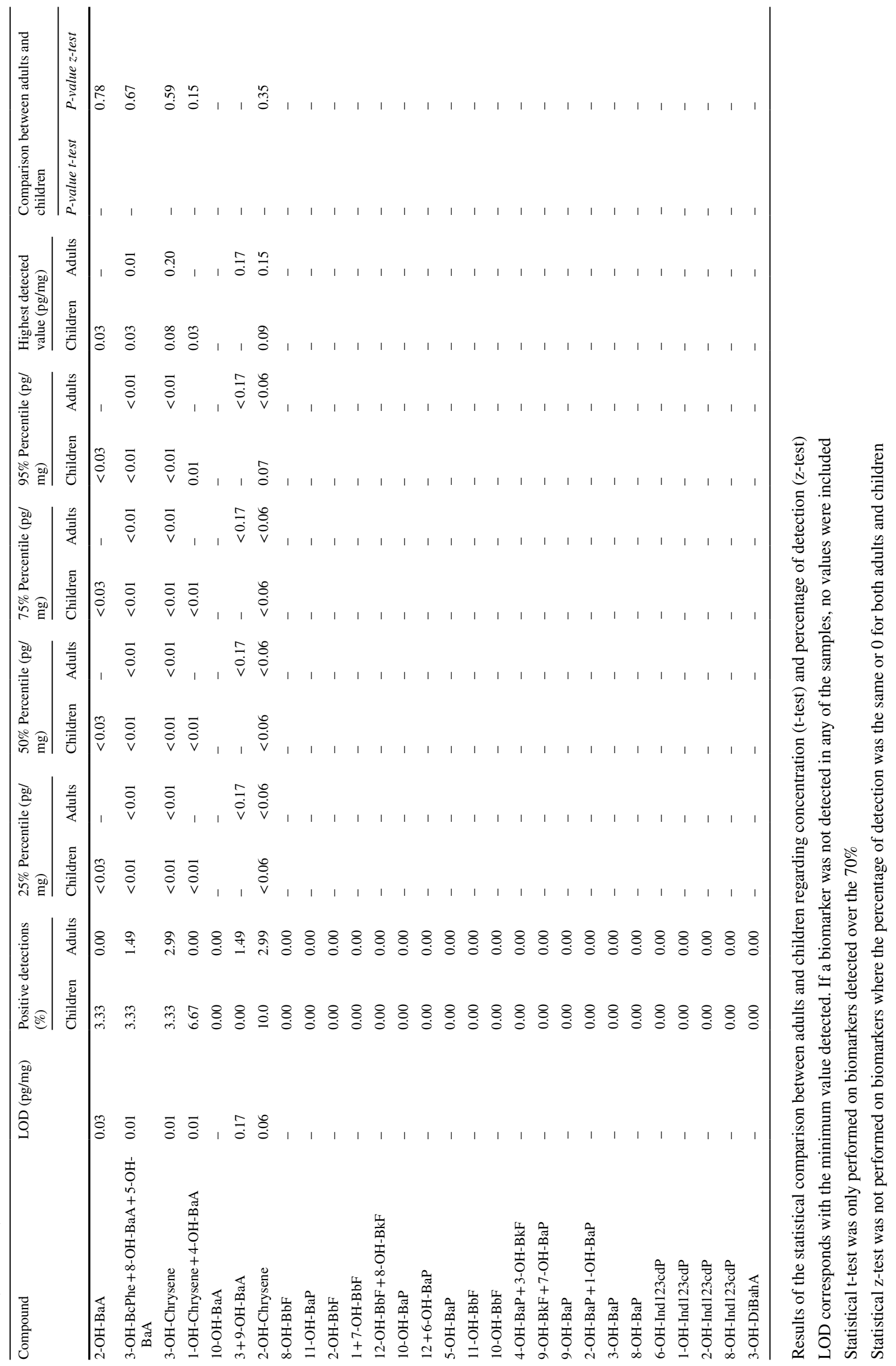




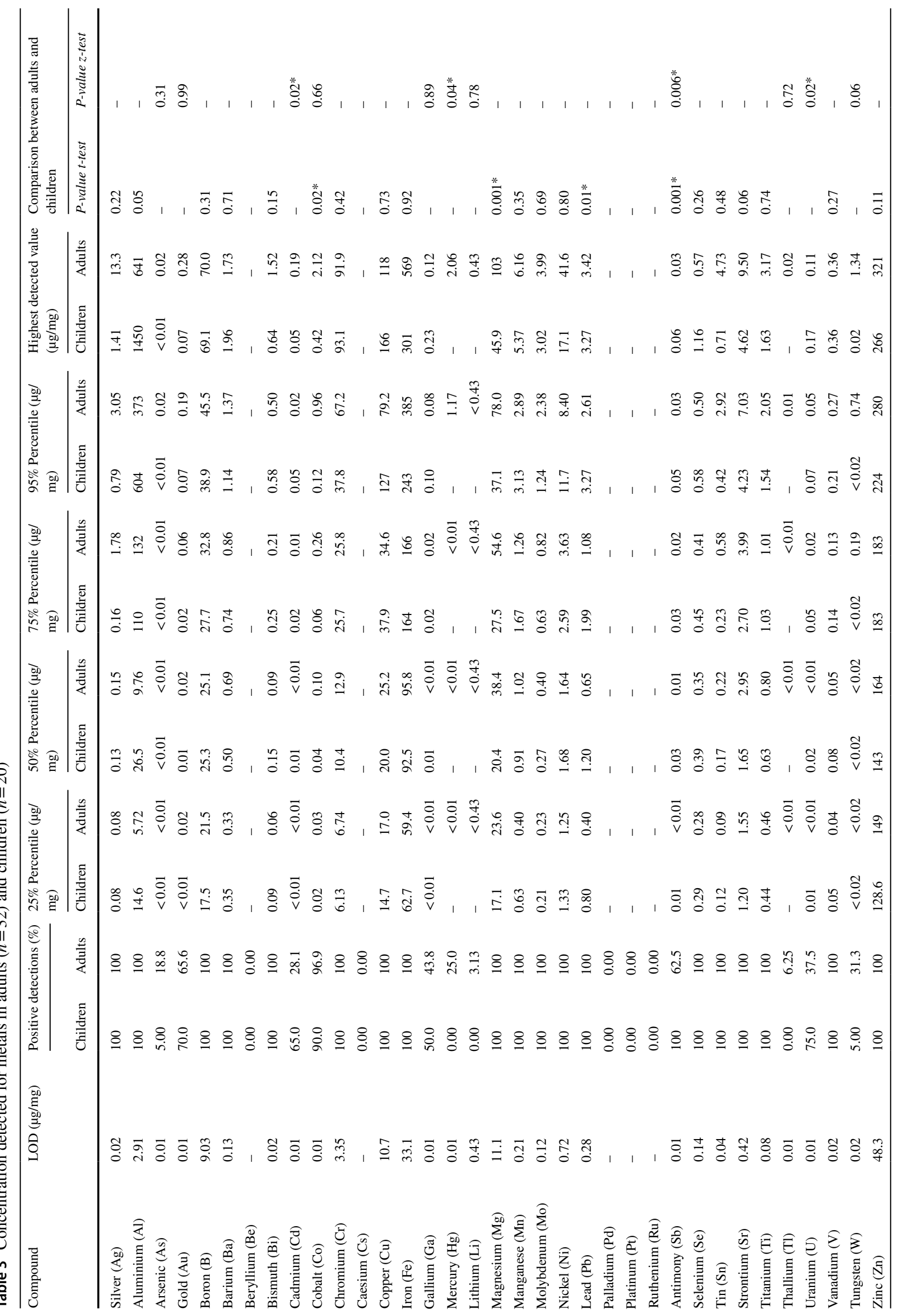


compounds (DMP, propiconazole, 2,4-D, fipronil sulfone, diflufenican, prosulfocarb, terbutryn and 1-(3,4-dichlorophenyl)-urea) presented higher concentrations in children. The other 7 ( $y-\mathrm{HCH}, \mathrm{DEP}, \mathrm{TCPy}$, $3 \mathrm{Me} 4 \mathrm{NP}, \mathrm{ClCF}_{3} \mathrm{CA}, \mathrm{MCPA}$ and metolachlor) showed higher concentrations in adults. For the 131 biomarkers that presented different detection rate between adults and children, this difference was significant for 33 (13 more detected in children vs 20 more detected in adults) (Fig. 2). When children and adults were considered separately regarding correlation with age, 10 biomarkers (y-HCH, thiabendazole, azoxystrobin, mecoprop, 2,4D, imidacloprid, carbendazim, 1-(3,4-dichlorophenyl) urea, bisphenol A and bisphenol S) showed significant negative correlations between age and exposure in children. Only two compounds (fipronil and atrazine desthyl) showed significant positive correlation. In adults, 11 biomarkers $\left(\gamma-\mathrm{HCH}, \mathrm{PCP}, \mathrm{HCB}, 3 \mathrm{Me} 4 \mathrm{NP}, \mathrm{Cl}_{2} \mathrm{CA}\right.$, 3-PBA, thiabendazole, pyraclostrobin, carbendazim, boscalid and 1-(3,4-dichlorophenyl)-3-methyl-urea) showed significant positive correlations (Table 4).

(2) Only 2 parent PAHs, chrysene and indenol[1,2,3-cd] pyrene, presented significantly different concentrations between adults and children (Table 2). Chrysene was more detected in children and indenol[1,2,3-cd] pyrene in adults. When children and adults were considered separately regarding correlation with age, two parent PAH (benz(a)anthracene and benzo(k)fluoranthene) and two PAH metabolites (1-OH-naphthalene and 2-OH-Fluorene) showed significant negative correlations in children. In adults, only one parent PAH (Benzo(ghi)perylene) and two metabolites (2-OHnaphthalene and 4-OH-phenanthrene) showed significant correlations: negative coefficients for Benzo(ghi) perylene and 4-OH-phenanthrene and positive for 2-OH-naphthalene (Table 5). Thirty four biomarkers presented differences in detection rate between adults and children, which were significant for 3 biomarkers (acenaphthene and 1-OH-phenanthrene more detected in adults and fluoranthene in children).

(3) Four metals (cobalt, magnesium, lead and antimony) showed significant differences between adults and children (Table 3), being children more exposed to lead and antimony. In children, age was negatively correlated with tin concentration in hair. In adults, age was negatively correlated with boron and bismuth concentration in hair (Table 6). For the 11 biomarkers that presented different detection rate between adults and children, this difference was significant for 4 (mercury was more detected in adults and cadmium, antimony and uranium in children). 


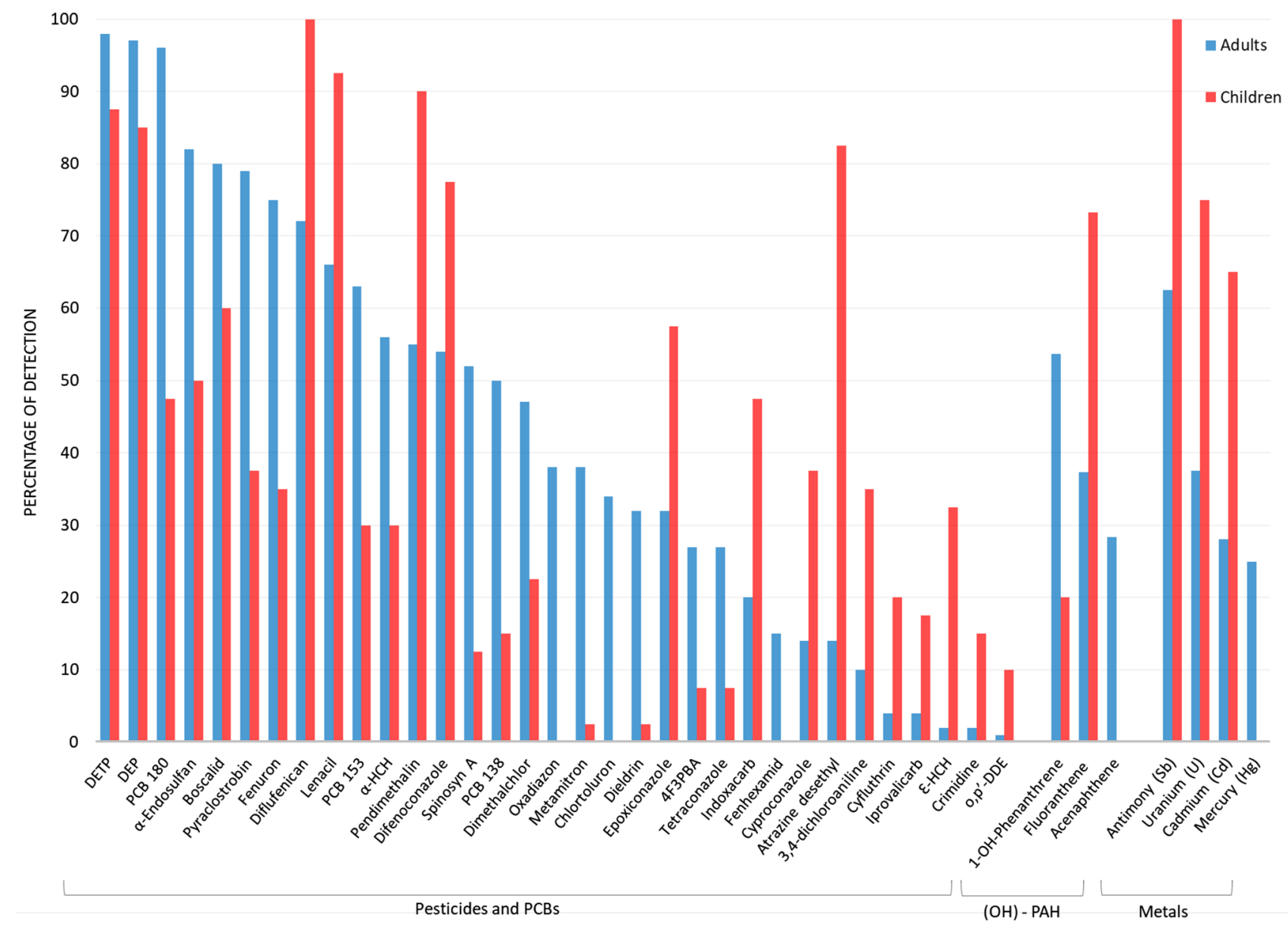

Fig. 2 Percentage of detection of biomarkers presenting significant difference (z-test) between children and adults

\section{Discussion}

Targeting 261 biomarkers, the present study is the first one assessing exposure to such a wide range of pollutants in human. The average number of biomarkers detected in children and adults was 88 and 94, respectively, and reached 104 and 121 at the maximum (Fig. 1). These results clearly highlight that simultaneous exposure to different classes of pollutants (both organic and metals) can be considered as a baseline in modern human, as previously suggested with a lower number of biomarkers in recent studies conducted on different adult and children populations (Beranger et al.
2018; Iglesias-González et al. 2020; Palazzi et al. 2019, 2018; Peng et al. 2020a). In parallel, an increasing amount of literature is pointing out the effect of multiple exposure. Many studies demonstrated that synergies between several pollutants might lead to different effects than each pollutant separately. For instance, Silva et al. (2002) demonstrated on yeast cell culture that a mixture of 8 contaminants (including organochlorines and bisphenol A) displayed estrogenic activity 20 times higher than the summed effect of each chemical alone at equivalent concentration. In another study conducted on mussels, Song et al. (2016) demonstrated that combination of benzo(a)pyrene (polycyclic aromatic 
Table 4 Pearson and Spearman correlation coefficients and p-values between concentration and age of pesticides and bisphenols detected $\geq 70 \%$ of the samples

\begin{tabular}{|c|c|c|c|c|c|c|c|c|}
\hline \multirow[t]{3}{*}{ Compound } & \multicolumn{4}{|l|}{ Children } & \multicolumn{4}{|l|}{ Adults } \\
\hline & \multicolumn{2}{|c|}{ Pearson correlation } & \multicolumn{2}{|c|}{ Spearman correlation } & \multicolumn{2}{|c|}{ Pearson correlation } & \multicolumn{2}{|c|}{ Spearman correlation } \\
\hline & Coefficient & p-value & Coefficient & $p$-value & Coefficient & p-value & Coefficient & $p$-value \\
\hline$y-\mathrm{HCH}$ & -0.38 & $0.02 *$ & -0.31 & 0.05 & 0.2 & $0.03 *$ & 0.24 & $0.01 *$ \\
\hline$\alpha$-Endosulfan & - & - & - & - & 0.09 & 0.36 & -0.05 & 0.57 \\
\hline Pentachlorophenol (PCP) & -0.24 & 0.14 & -0.19 & 0.24 & 0.05 & 0.56 & 0.38 & $<0.001 *$ \\
\hline Hexachlorobenzene (HCB) & -0.28 & 0.08 & -0.24 & 0.14 & 0.31 & $0.001 *$ & 0.33 & $<0.001 *$ \\
\hline DMP & 0.00 & 1.00 & 0.09 & 0.60 & -0.04 & 0.65 & 0.15 & 0.1 \\
\hline DEP & 0.09 & 0.57 & -0.19 & 0.24 & 0.02 & 0.83 & 0.01 & 0.88 \\
\hline DETP & 0.16 & 0.33 & 0.01 & 0.94 & -0.003 & 0.98 & 0.01 & 0.92 \\
\hline ТCPy & 0.19 & 0.26 & 0.16 & 0.34 & 0.09 & 0.29 & 0.05 & 0.58 \\
\hline P-Nitrophenol (PNP) & 0.20 & 0.21 & 0.17 & 0.29 & 0.19 & 0.05 & 0.16 & 0.09 \\
\hline $3 \mathrm{Me} 4 \mathrm{NP}$ & -0.09 & 0.60 & -0.16 & 0.34 & 0.16 & 0.08 & 0.32 & $<0.001^{*}$ \\
\hline $\mathrm{Cl}_{2} \mathrm{CA}$ & -0.08 & 0.64 & -0.23 & 0.17 & 0.112 & 0.24 & 0.19 & $0.04 *$ \\
\hline $\mathrm{ClCF}_{3} \mathrm{Ca}$ & 0.25 & 0.12 & -0.22 & 0.19 & 0.16 & 0.08 & 0.14 & 0.14 \\
\hline 3-PBA & 0.04 & 0.80 & -0.24 & 0.15 & -0.01 & 0.93 & 0.28 & $0.003 *$ \\
\hline PCB180 & - & - & - & - & 0.39 & $<0.001 *$ & 0.53 & $<0.001 *$ \\
\hline Difenoconazole & -0.19 & 0.24 & -0.09 & 0.60 & - & - & - & - \\
\hline Propiconazole & -0.01 & 0.94 & -0.14 & 0.38 & -0.05 & 0.63 & -0.07 & 0.47 \\
\hline Thiabendazole & -0.31 & 0.06 & -0.52 & $<0.001^{*}$ & -0.01 & 0.89 & 0.25 & $0.01 *$ \\
\hline Azoxystrobin & -0.37 & $0.02 *$ & -0.57 & $<0.001^{*}$ & 0.004 & 0.96 & 0.14 & 0.13 \\
\hline Pyraclostrobin & - & - & - & - & 0.24 & $0.01^{*}$ & 0.32 & $0.001 *$ \\
\hline Trifloxystrobin & - & - & - & - & 0.05 & 0.6 & 0.16 & 0.08 \\
\hline Mecroprop & -0.42 & $0.01 *$ & -0.57 & $0.002^{*}$ & 0.09 & 0.35 & 0.1 & 0.27 \\
\hline MCPA & -0.09 & 0.57 & -0.27 & 0.09 & 0.17 & 0.07 & 0.09 & 0.33 \\
\hline $2,4-\mathrm{D}$ & -0.39 & $0.01 *$ & -0.54 & $<0.001^{*}$ & 0.11 & 0.26 & 0.1 & 0.29 \\
\hline Trifluralin & -0.29 & 0.08 & -0.27 & 0.10 & 0.04 & 0.65 & 0.03 & 0.78 \\
\hline Pendimethalin & -0.04 & 0.82 & 0.03 & 0.86 & - & - & - & - \\
\hline Imidacloprid & -0.38 & $0.02 *$ & -0.59 & $<0.001 *$ & - & - & - & - \\
\hline Fipronil & 0.37 & $0.02 *$ & 0.28 & 0.08 & -0.06 & 0.52 & -0.05 & 0.58 \\
\hline Fipronil sulfone & 0.30 & 0.07 & 0.21 & 0.20 & -0.05 & 0.62 & -0.07 & 0.43 \\
\hline Carbendazim & -0.24 & 0.14 & -0.58 & $<0.001^{*}$ & -0.02 & 0.81 & 0.19 & $0.04 *$ \\
\hline Propoxur & - & - & - & - & 0.07 & 0.44 & 0.16 & 0.09 \\
\hline Boscalid & - & - & - & - & 0.11 & 0.23 & 0.33 & $<0.001 *$ \\
\hline Diflufenican & -0.01 & 0.94 & -0.26 & 0.11 & 0.13 & 0.17 & 0.08 & 0.41 \\
\hline Prosulfocarb & -0.18 & 0.28 & -0.04 & 0.82 & -0.003 & 0.98 & -0.06 & 0.56 \\
\hline Atrazine desthyl & 0.44 & $0.001 *$ & 0.30 & 0.07 & - & - & - & - \\
\hline Terbutryn & -0.13 & 0.41 & -0.22 & 0.18 & -0.07 & 0.43 & 0.09 & 0.35 \\
\hline 1-(3,4-dichlorophenyl)-3-methyl-urea & -0.13 & 0.44 & -0.08 & 0.65 & 0.22 & $0.02 *$ & 0.18 & 0.05 \\
\hline 1-(3,4-dichlorophenyl)-urea & -0.27 & 0.10 & -0.46 & $<0.001^{*}$ & -0.12 & 0.2 & -0.07 & 0.48 \\
\hline Fenuron & - & - & - & - & -0.06 & 0.55 & 0.02 & 0.86 \\
\hline Metolachlor & -0.06 & 0.72 & -0.06 & 0.73 & 0.1 & 0.3 & 0.12 & 0.21 \\
\hline Lenacil & 0.21 & 0.20 & 0.01 & 0.96 & - & - & - & - \\
\hline Bisphenol A & -0.37 & $0.02 *$ & -0.60 & $<0.001 *$ & -0.04 & 0.65 & 0.01 & 0.93 \\
\hline Bisphenol S & -0.20 & 0.21 & -0.76 & $<0.001^{*}$ & 0.19 & 0.04 & 0.18 & 0.12 \\
\hline
\end{tabular}

If a compound does not show a value in the table is because it was not detected $\geq 70 \%$ of the samples of the group

${ }^{*} p$-value $<0.05$ 
Table 5 Pearson and Spearman correlation coefficients and p-values between concentration and age of nicotine, cotinine and of the (OH)-PAHs detected $\geq 70 \%$ of the samples

\begin{tabular}{|c|c|c|c|c|c|c|c|c|}
\hline \multirow[t]{3}{*}{ Compound } & \multicolumn{4}{|c|}{ Children $(n=30)$} & \multicolumn{4}{|c|}{ Adults $(n=67)$} \\
\hline & \multicolumn{2}{|c|}{ Pearson correlation } & \multicolumn{2}{|c|}{ Spearman correlation } & \multicolumn{2}{|c|}{ Pearson correlation } & \multicolumn{2}{|c|}{ Spearman correlation } \\
\hline & Coefficient & p-value & Coefficient & $p$-value & Coefficient & $p$-value & Coefficient & $p$-value \\
\hline Nicotine & -0.01 & 0.95 & -0.27 & 0.16 & 0.06 & 0.63 & -0.14 & 0.31 \\
\hline Cotinine & -0.22 & 0.26 & -0.28 & 0.14 & -0.002 & 0.99 & -0.03 & 0.79 \\
\hline Fluoranthene & -0.20 & 0.32 & -0.23 & 0.26 & - & - & - & - \\
\hline Benz[a]anthracene & -0.48 & $0.01 *$ & -0.45 & $0.02 *$ & - & - & - & - \\
\hline Chrysene & -0.11 & 0.61 & -0.38 & 0.05 & -0.07 & 0.58 & -0.16 & 0.23 \\
\hline Benzo(b)fluoranthene & - & - & - & - & -0.18 & 0.15 & -0.12 & 0.33 \\
\hline Benzo(k)fluoranthene & -0.40 & $0.04 *$ & -0.35 & 0.08 & -0.01 & 0.96 & -0.03 & 0.82 \\
\hline Indeno[1,2,3-cd]pyrene & 0.24 & 0.23 & 0.21 & 0.29 & 0.11 & 0.41 & 0.19 & 0.13 \\
\hline Benzo(ghi)perylene & -0.17 & 0.42 & -0.22 & 0.28 & -0.17 & 0.19 & -0.26 & $0.04 *$ \\
\hline 1-OH-Naph & -0.49 & $0.01 *$ & -0.48 & $0.01 *$ & 0.16 & 0.22 & 0.19 & 0.12 \\
\hline 2-OH-Naph & 0.10 & 0.59 & 0.13 & 0.50 & 0.19 & 0.11 & 0.28 & $0.03 *$ \\
\hline 9-OH-Fluorene & -0.10 & 0.63 & -0.11 & 0.58 & -0.22 & 0.08 & -0.16 & 0.21 \\
\hline 2-OH-Fluorene & -0.51 & $<0.001 *$ & -0.53 & $0.004 *$ & 0.11 & 0.38 & 0.15 & 0.23 \\
\hline 4-OH-Phenanthrene & 0.31 & 0.10 & 0.04 & 0.80 & -0.28 & $0.02 *$ & -0.32 & $0.01 *$ \\
\hline
\end{tabular}

If a compound does not show a value in the table is because it was not detected $\geq 70 \%$ of the samples of the group

${ }^{*} p$-value $<0.05$

hydrocarbon) and dichlorodiphenyltrichloroethane (DDT, organochlorine pesticide)-induced dysregulation of proteins involved in gills' osmotic regulation and gonad metabolism, which were not affected when each chemical was alone. Mixtures can therefore induce adverse effects that were not observed, or only observed at higher level of exposure, with individual pollutants (Silva et al. 2002; Song et al. 2016; Starr et al. 2012; Shukla et al. 2017; Christen et al. 2014; Kortenkamp 2007; Orton et al. 2014). Consequently, the "safe" level of exposure established for a specific pollutant could actually lead to adverse effects due to co-exposure to other chemicals, and should be re-evaluated accordingly by regulatory agencies, who besides highlighted the need of methodologies allowing for the analysis of multiple pollutants simultaneously (Carlin et al. 2013; Kortenkamp 2014; Kostoff et al. 2018).
A detailed comparison with other studies was conducted on biomarkers common to several articles and detected in $>50 \%$ of the subjects. The median concentrations suggested equivalent or lower exposure levels of the population under study for most of the organic pollutants that could be compared: organochlorines, PCBs, organophosphates, pyrethroids, pesticides, nicotine, cotinine and PAHs (Fig. 3 and SI). Results obtained for metals were more balanced, since five metals presented here median concentration equivalent to, or above the highest values reported in the literature: chromium, copper, iron, aluminum and nickel (Fig. 3 and SI).

Metal emissions to the environment are predominantly derived from fuel combustion, coal-fired power plant and industrial processes (particularly metal production) (Rowbotham et al. 2000; Reis et al. 2014). Although no data 
Table 6 Pearson and Spearman correlation coefficients and $p$-values between concentration and age of metals detected $\geq 70 \%$ of the samples

\begin{tabular}{|c|c|c|c|c|c|c|c|c|}
\hline \multirow[t]{3}{*}{ Compound } & \multicolumn{4}{|c|}{ Children $(n=20)$} & \multicolumn{4}{|c|}{ Adults $(n=32)$} \\
\hline & \multicolumn{2}{|c|}{ Pearson correlation } & \multicolumn{2}{|c|}{ Spearman correlation } & \multicolumn{2}{|c|}{ Pearson correlation } & \multicolumn{2}{|c|}{ Spearman correlation } \\
\hline & Coefficient & $p$-value & Coefficient & $p$-value & Coefficient & $p$-value & Coefficient & $p$-value \\
\hline Silver (Ag) & 0.28 & 0.24 & -0.05 & 0.84 & 0.11 & 0.56 & 0.02 & 0.92 \\
\hline Aluminium (Al) & 0.10 & 0.66 & -0.34 & 0.15 & 0.12 & 0.52 & -0.20 & 0.27 \\
\hline Gold (Au) & -0.10 & 0.69 & -0.08 & 0.73 & - & - & - & - \\
\hline Boron (B) & 0.15 & 0.53 & 0.35 & 0.13 & -0.29 & 0.10 & -0.37 & $0.04 *$ \\
\hline Barium (Ba) & 0.02 & 0.93 & 0.11 & 0.65 & -0.02 & 0.89 & -0.08 & 0.67 \\
\hline Bismuth (Bi) & -0.05 & 0.82 & -0.28 & 0.22 & -0.39 & $0.02 *$ & -0.37 & $0.04 *$ \\
\hline Cobalt (Co) & 0.34 & 0.15 & 0.17 & 0.47 & 0.14 & 0.44 & 0.02 & 0.91 \\
\hline Chromium (Cr) & 0.26 & 0.26 & 0.14 & 0.56 & -0.16 & 0.39 & -0.11 & 0.56 \\
\hline Copper $(\mathrm{Cu})$ & -0.06 & 0.79 & -0.05 & 0.84 & -0.16 & 0.39 & 0.06 & 0.76 \\
\hline Iron $(\mathrm{Fe})$ & 0.12 & 0.60 & 0.08 & 0.73 & -0.16 & 0.40 & -0.08 & 0.67 \\
\hline Magnesium (Mg) & 0.06 & 0.80 & 0.02 & 0.92 & -0.26 & 0.14 & -0.16 & 0.37 \\
\hline Manganese (Mn) & 0.06 & 0.81 & -0.14 & 0.55 & 0.06 & 0.76 & 0.02 & 0.93 \\
\hline Molybdenum (Mo) & 0.28 & 0.23 & 0.20 & 0.40 & -0.12 & 0.50 & -0.13 & 0.47 \\
\hline Nickel (Ni) & 0.10 & 0.68 & 0.23 & 0.92 & 0.07 & 0.69 & -0.05 & 0.77 \\
\hline Lead $(\mathrm{Pb})$ & -0.38 & 0.10 & -0.44 & 0.05 & -0.22 & 0.23 & -0.12 & 0.51 \\
\hline Antimony (Sb) & -0.18 & 0.45 & -0.31 & 0.18 & -0.10 & 0.59 & -0.17 & 0.36 \\
\hline Selenium (Se) & 0.07 & 0.76 & 0.20 & 0.39 & -0.29 & 0.11 & -0.33 & 0.07 \\
\hline Tin (Sn) & -0.16 & 0.49 & -0.46 & $0.04 *$ & -0.10 & 0.62 & -0.02 & 0.92 \\
\hline Strontium (Sr) & 0.22 & 0.36 & 0.32 & 0.17 & -0.02 & 0.90 & -0.03 & 0.89 \\
\hline Titanium (Ti) & 0.24 & 0.32 & 0.22 & 0.36 & 0.11 & 0.56 & -0.06 & 0.74 \\
\hline Uranium (U) & 0.08 & 0.75 & 0.23 & 0.33 & - & - & - & - \\
\hline Vanadium (V) & 0.44 & 0.05 & 0.34 & 0.15 & -0.23 & 0.20 & -0.25 & 0.17 \\
\hline Zinc (Zn) & 0.40 & 0.08 & 0.35 & 0.13 & 0.14 & 0.46 & 0.22 & 0.23 \\
\hline Zirconium (Zr) & -0.14 & 0.57 & -0.43 & 0.06 & 0.06 & 0.76 & -0.20 & 0.26 \\
\hline
\end{tabular}

If a compound does not show a value in the table is because it was not detected $\geq 70 \%$ of the samples of the group

${ }^{*} p$-value $<0.05$

were collected in the present study to investigate the possible sources of exposure to metals (which was beyond the scope of this study), the contribution of the intense industrial activity (e.g. oil refinery, metal recycling, alloys and steal production) in the close vicinity of Grand-Synthe to metal exposure cannot be excluded. The results were particularly of concern for chromium, which is the most toxic of the metals pointed out here, and which presented concentration in hair one order of magnitude higher than values reported in the other studies (Fig. 3 and SI). Although metals concentration in hair does not allow to conclude on the risk associated with exposure, the present results suggest that specific attention has to be drawn to metal exposure in this population, particularly chromium.

In parallel to comparing each biomarker "one by one" between different studies, the use of multi-residue methods, which provide more comprehensive information on exposome, also allows the use of more sophisticated statistical analysis such as principal component analysis (PCA). Nevertheless, this approach can only be used to compare populations in which the same biomarkers were analyzed. 
The results obtained in the present study were therefore compared to previous studies conducted by our team with similar methodologies, on children and adults, in France and in China (Beranger et al. (2018), Iglesias-González et al. (2020) and Peng et al. (2020a)). Concerning children exposure to pollutants of group 1 (pesticides and PCBs), although the subjects from Grande-Synthe were not clearly separated from children living in other parts of France, the location of this group on the left part of the figure suggests lower global exposure (Fig. 4a). In particular, 3-PBA and $\mathrm{Cl}_{2} \mathrm{CA}$, which were the variables that contributed the most to the PCA, presented the lowest median concentration in GrandeSynthe compared to the other French children $(0.9 \mathrm{pg} / \mathrm{mg}$ vs $2.36 \mathrm{pg} / \mathrm{mg}$ for $3-P B A$ and $0.89 \mathrm{pg} / \mathrm{mg}$ vs $2.83 \mathrm{pg} / \mathrm{mg}$ for $\mathrm{Cl}_{2} \mathrm{CA}$ ).

For adults, PCA revealed clearly separated clusters between China and France, highlighting different exposome between the countries. Moreover, although the two French groups were not clearly separated, the position of the ellipse corresponding to Grande-Synthe population suggests that people from this group had on average lower global exposure than the other French subjects (Fig. 4b). The new policies implemented in Grande-Synthe by the cityhall in regard to the nutrition of the population could explain the lower exposure compared to other regions. Since 2011, the city of Grande-Synthe implemented a 100\% organic diet in the schools and, since 2018, the city is producing their own organic vegetables (Mairie de Grande-Synthe). Most of the biomarkers that were highly detected in this study are actually still found in many consumable products, especially from animal origin and public water in France (ANSES 2019). This suggests that exposure of this population would be due to the consumption of food from national or international market rather than to local contamination.

Concerning polycyclic aromatic hydrocarbons (PAH), which are mainly produced from fossil fuel combustion (e.g. in transports and industrial activities) and are usually considered reliable biomarkers of "global pollution", the data obtained for adults in the present study were compared to results obtained from adult women living in 2 Chinese cities (Palazzi et al. 2018). This comparison clearly showed lower concertation of biomarkers in the hair of adults in Grande-Synthe (Fig. 5a), suggesting lower global exposure to PAH. For instance, the median concentration of benzo(a)anthracene in the Chinese cities was $0.69 \mathrm{pg} / \mathrm{mg}$ (Dalian) and $1.58 \mathrm{pg} / \mathrm{mg}$ (Baoding) compared to $0.09 \mathrm{pg} / \mathrm{mg}$ in Grande-Synthe. Similarly, benzo(k) fluoranthene concentration amounted to $0.56 \mathrm{pg} / \mathrm{mg}$ and $1.32 \mathrm{pg} / \mathrm{mg}$ in Dalian in Baoding, respectively, compared to $0.23 \mathrm{pg} / \mathrm{mg}$ in the French city.

The data concerning PAH in children living in GrandeSynthe were compared to results obtained from children living in Paris (Palazzi et al. 2019). Once again, despite a slight overlap between the 2 groups, the results suggest lower global exposure of the children living in GrandSynthe (Fig. 5b).

As mentioned above, PAH are considered reliable biomarkers of exposure to global pollution, which on the other hand, is often assessed by atmospheric fine particles. The concentration values of atmospheric $\mathrm{PM}_{10}$ at the time of hair collection in the different studies used here for comparison were, respectively, $43.8 \mu \mathrm{g} / \mathrm{m}^{3}$ for Paris, $54.8 \mu \mathrm{g} /$ $\mathrm{m}^{3}$ for Dalian and $120 \mu \mathrm{g} / \mathrm{m}^{3}$ for Baoding, compared to $4.37 \mu \mathrm{g} / \mathrm{m}^{3}$ for Grande-Synthe (AQICN 2020), which suggests lower pollution in Grande-Synthe and is therefore in line with the results obtained from hair analysis.

As mentioned above, synergies between different chemicals can modify and possibly increase their toxicity when they are in combination, which is commonly known as the "cocktail effect". A pollutant might therefore induce (trigger or exacerbate) different biological effects depending on the background exposome accompanying it. As highlighted in the present study, exposome can differ in both composition and intensity between different population groups. This might lead to different effect of one specific pollutant for populations having different background exposome (on top of genetic/susceptibility differences) and explain contradictory results between different studies. Eventually, the possible importance of background exposome on pollutants toxicity strongly suggests that in the study of exposure-associated effects, multi-residue methods have to be privileged to better document the background exposome of the population under study.

The number of biomarkers of group 1 presenting significantly different detection frequency between adults and children $(n=33)$ was much higher than the number that would be due to chance $(n=6.5)$. Similarly, the biomarkers presenting significantly different concentration between children and adults $(n=15)$ were ten times higher than the number that would be due to chance $(n=1.5)$. No unilateral tendency was observed and the most exposed group (children or adults) was different depending on biomarkers (Fig. 2). This 
(a)

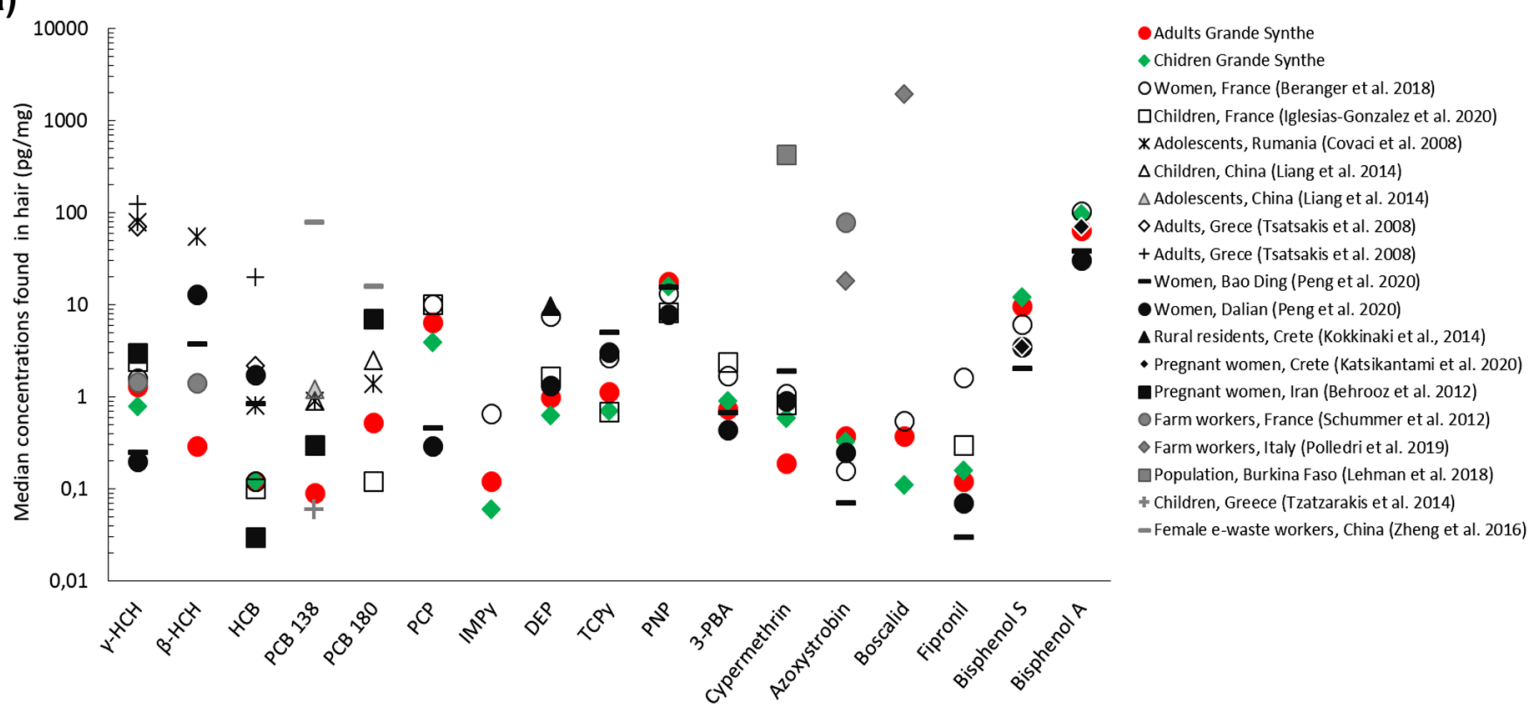

(b)

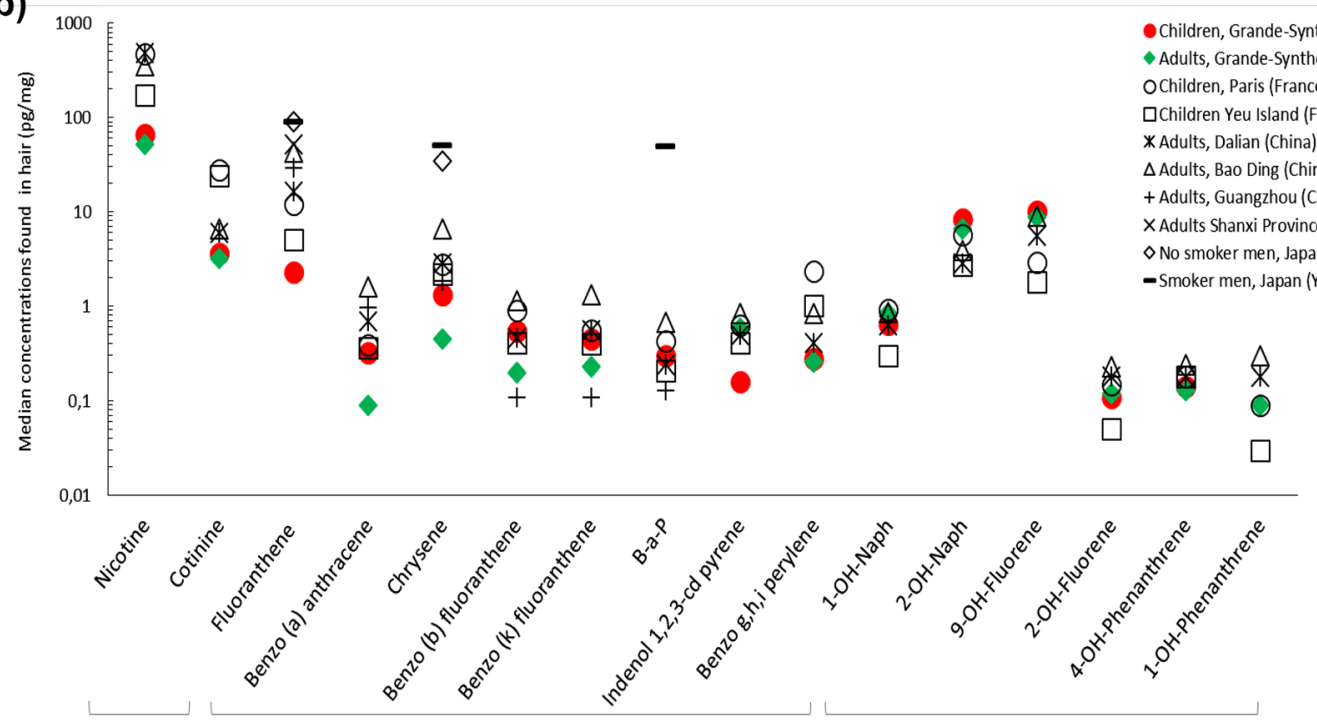

Nicotine and Cotinine

Parent PAH

PAH metabolites

(c)

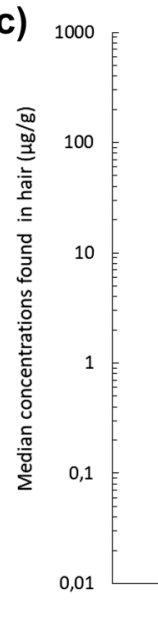


4 Fig. 3 Comparison of the median values of the present study versus studies performed in France and worldwide for a the first group (pesticides, PCBs and bisphenols), b nicotine, cotinine, PAHs and metabolites and $\mathbf{c}$ metals

suggests that the differences observed here might rather be due to different behaviour between adults and children (e.g. diet) than to global contamination of the environment that would affect children and adults in a more similar manner.

Differences between adults and children were much less marked for PAH and metals, possibly suggesting that specific behaviour (diet, habits...) would play a lesser role in exposure to these pollutants than environmental contamination. This hypothesis is in line with previous studies reporting that populations living in areas with different levels of atmospheric pollution had significantly different concentration of PAH in hair (Palazzi et al. 2018, 2019).

In biomarkers of group 1 and 2, the number of significant correlations between age and biomarker concentration observed among adults and children separately (20 and 24, respectively) was also greater than if due to chance (10 in total). In adults, almost all the significant associations were positive (Tables 4 and 5). For persistent pollutants such as $y-\mathrm{HCH}$, pentachlorophenol, hexachlorobenzene and PCB 180 , the positive association might be attributed to bioaccumulation over life, as it has already been described for such persistent pollutants (Geyer et al. 2000). In parallel, differences in lifestyle and particularly food preferences among the different age classes could also explain these associations. For non-persistent chemicals, bioaccumulation is unlikely and only age-specific behaviour may account for differences in exposure.

Contrary to adults, almost all the significant associations observed between age and biomarker concentration in children were negative (Tables 4 and 5). Here again, different behaviour between age classes, such as food preferences or hand-to-mouth behaviour in youngest children, may explain the inverse associations. For instance, the higher concentration of bisphenols $\mathrm{A}$ and $\mathrm{S}$ in the youngest children might be linked to their presence in toys and baby bottles. Actually, although bisphenol A has been substituted by its analogue bisphenol $\mathrm{S}$ in the European Union, many imported products still contain it, which eventually results in the presence of these two chemicals in children environment (Vandenberg et al. 2007; Wu et al. 2018; Žalmanová et al. 2016).

In parallel, other hypotheses may be proposed to explain the inverse associations between biomarkers concentration and age in children. For PAH that are often present as atmospheric pollution, the inverse association observed here could be explained by the height of the children, which is directly associated with age. As previously suggested by Palazzi et al. (2019) the higher exposure of younger children could be due to their closer proximity to the ground. This hypothesis is supported by several studies that demonstrated vertical gradient of PAH concentration with higher values close to the ground (Tao et al. 2007; Nakashima et al. 2014).

Higher exposure of younger children could also be explained by age-related metabolic and physiological differences, such as alveolar ventilation-to-body weight ratio and basal metabolic rate, which are inversely associated with age (Price et al. 2003; Griffiths et al. 1990; Molnar and Schutz 1997).

\section{Conclusion}

The present study is the first one to assess the exposure of children and adults belonging to the same population to such an extensive number of biomarkers from different chemical families with targeted methods. The results provide a comprehensive description of the chemical exposome of the population under study, highlighting the simultaneous exposure of each individual to many chemicals from different classes.

The results demonstrate how background exposure can differ depending on the population and support the use of multi-residue methods in order to better characterize exposome and highlight the specificities of the population under study.

This study also demonstrated differences between adults and children in the association between exposure and age: while adults seem to present higher concentrations at older ages, children seem to be more exposed at younger ages. This suggests that equivalent level exposure (e.g. due food and environmental contamination) would eventually lead to significantly different internal dose of pollutants between individuals within the same population. 
(a)

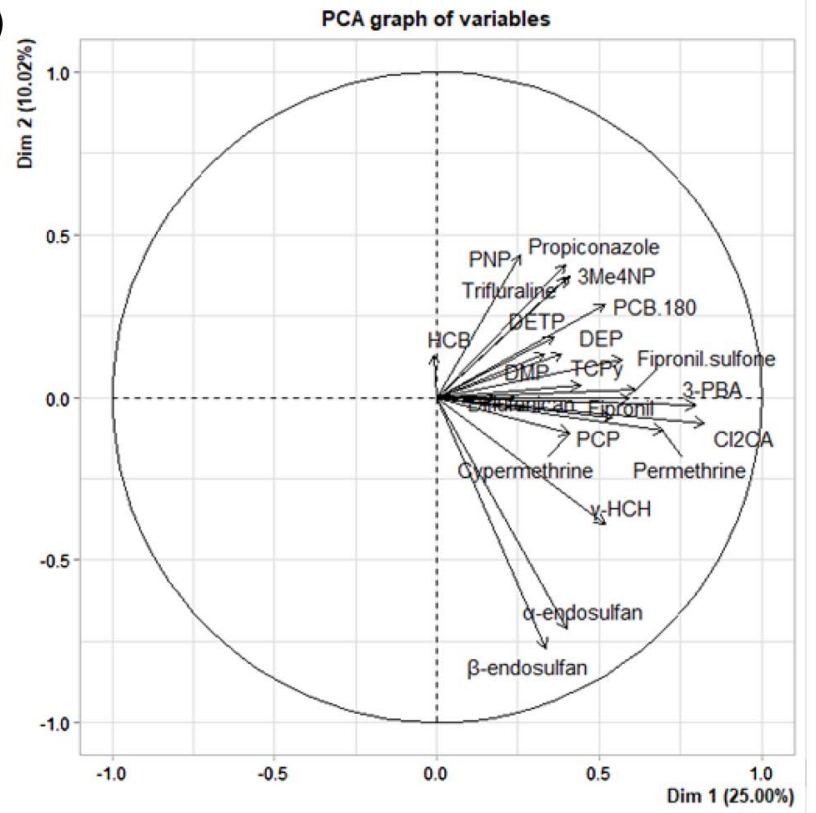

France (Iglesias-González et al., 2020)

Grande-Synthe

(b)

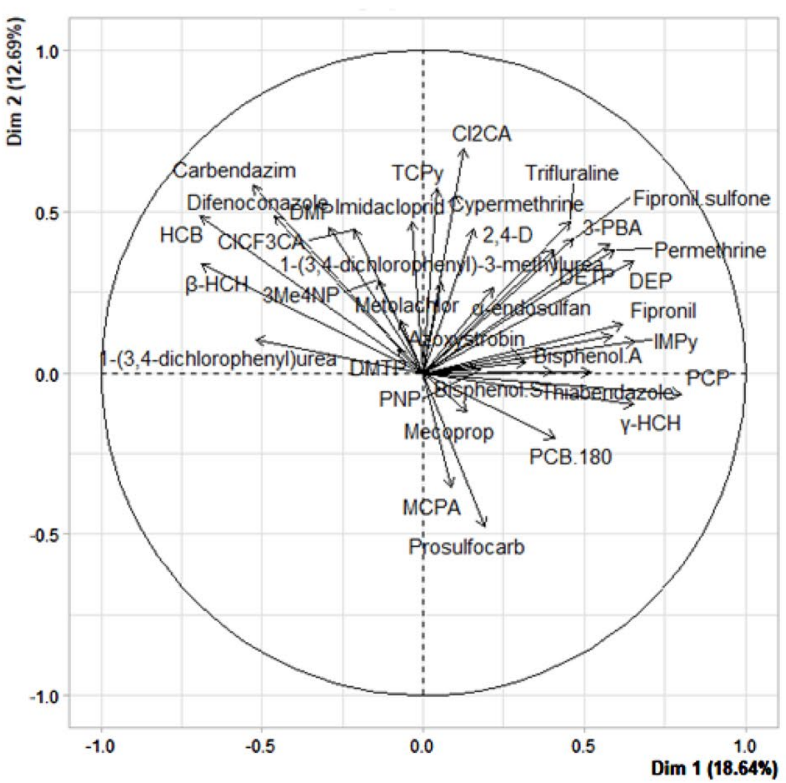

BaoDing (Peng et al., 2020)

DaLian (Peng et al., 2020)

France (Beranger et al., 2018)

Grande-Synthe

Fig. 4 Comparison of the exposure of $\mathbf{a}$ children (top) and $\mathbf{b}$ adults (bottom) to pesticides, PCBs and PBDEs between Grande-Synthe and other areas worldwide. Principal component analysis (Percentage of detection $\geq 70 \%$ ). On the left, projection of each variable's contribu-
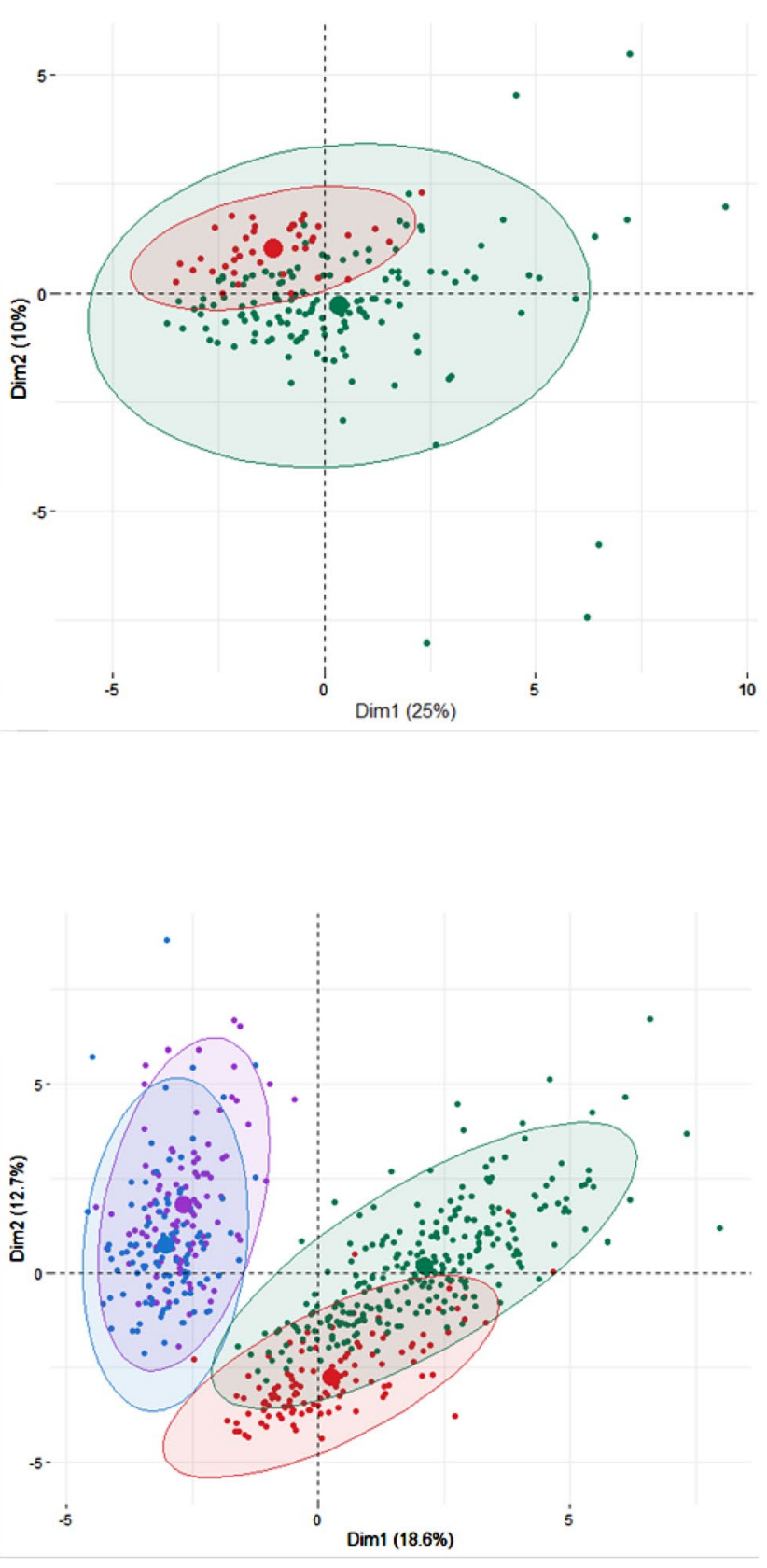

tion on dimension 1 and 2. On the right, representation of each individual plotted by points and clustered depending on their chemical exposure 
(a)

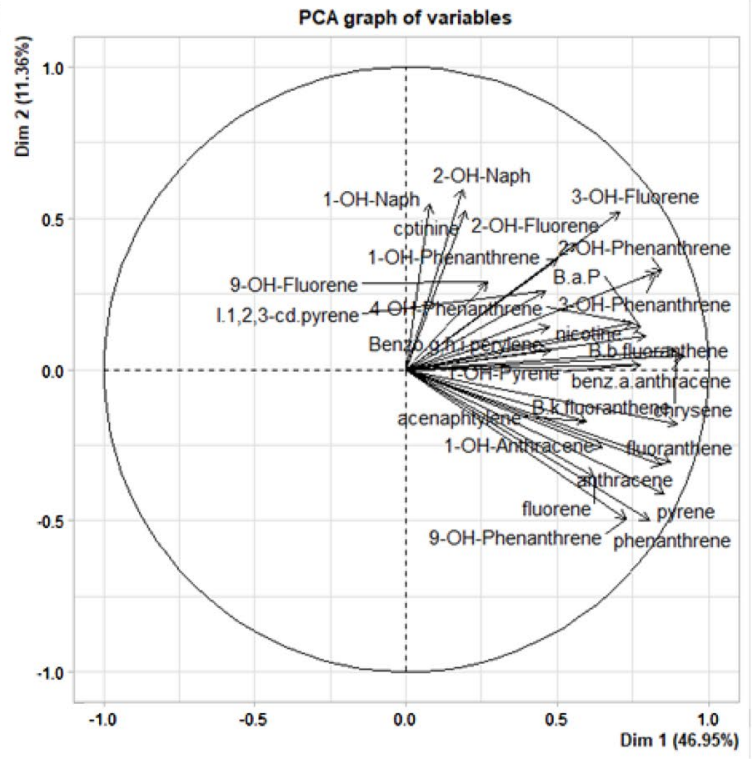

BaoDing (Palazzi et al., 2018)

DaLian (Palazzi et al., 2018)

Grande-Synthe

(b)

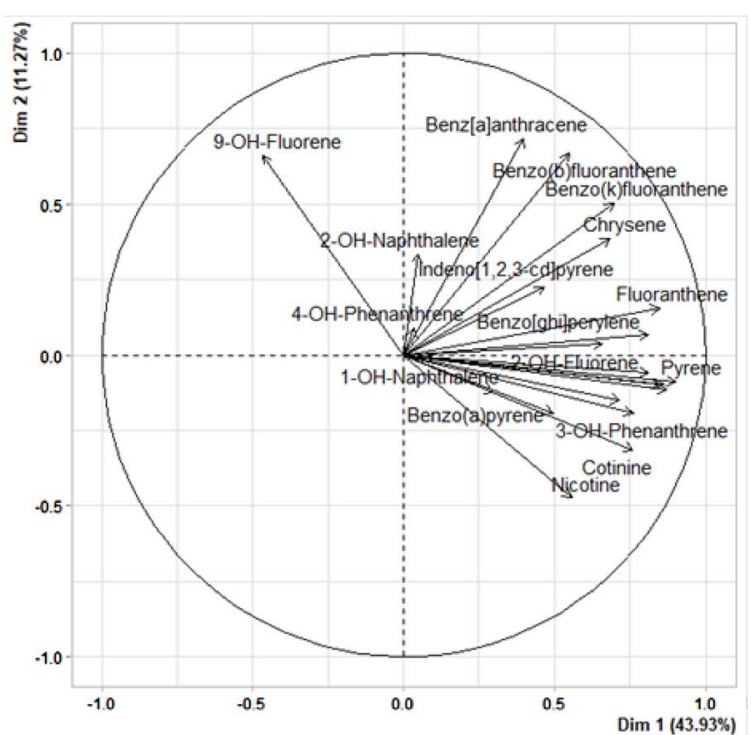

Grande-Synthe

Paris (Palazzi et al. 2019)

Fig. 5 Comparison of the exposure of $\mathbf{a}$ adults (top) and $\mathbf{b}$ children (bottom) to nicotine, cotinine, PAH and PAH metabolites between Grande-Synthe and other areas worldwide. Principal component analysis (Percentage of detection $\geq 70 \%$ ). On the left, projection of each
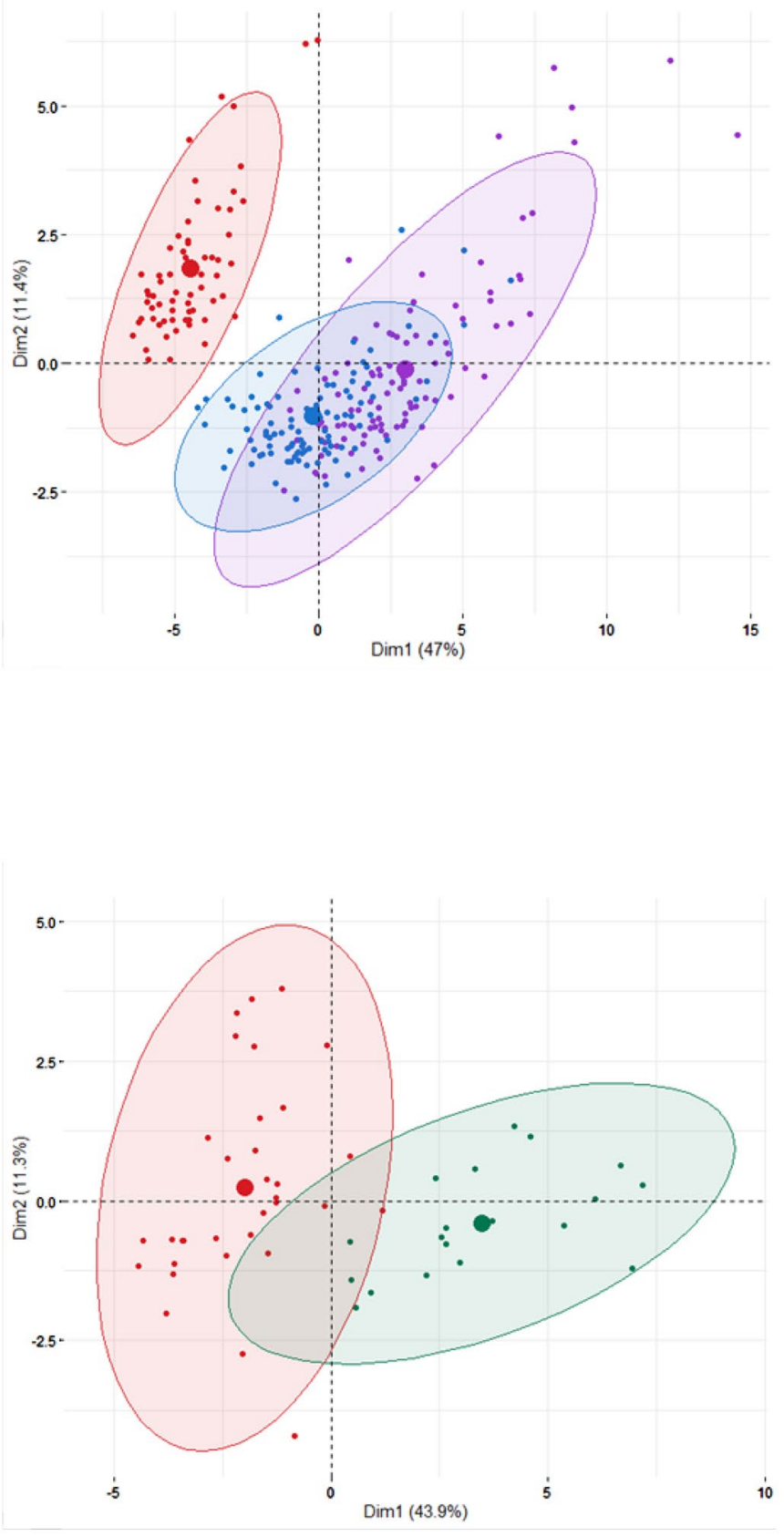

variable's contribution on dimension 1 and 2 . On the right, representation of each individual plotted by points and clustered depending on their chemical exposure 
Supplementary Information The online version contains supplementary material available at https://doi.org/10.1007/s12403-021-00444-2.

Acknowledgements The cost associated with hair sample analysis was mainly covered by the city of Grande-Synthe.

Data availability Participants of this study did not agree for their data to be shared publicly, so supporting data is not available.

\section{Declarations}

Conflict of interest The authors declare that they have no known competing financial interests or personal relationships that could have appeared to influence the work reported in this paper.

Consent to participate All the participants were duly informed about the study protocol and objectives and provided an informed consent.

Consent for publication We confirm that the manuscript has been read and approved by all named authors who agreed that the research was ready for submissions to a journal.

Open Access This article is licensed under a Creative Commons Attribution 4.0 International License, which permits use, sharing, adaptation, distribution and reproduction in any medium or format, as long as you give appropriate credit to the original author(s) and the source, provide a link to the Creative Commons licence, and indicate if changes were made. The images or other third party material in this article are included in the article's Creative Commons licence, unless indicated otherwise in a credit line to the material. If material is not included in the article's Creative Commons licence and your intended use is not permitted by statutory regulation or exceeds the permitted use, you will need to obtain permission directly from the copyright holder. To view a copy of this licence, visit http://creativecommons.org/licenses/by/4.0/.

\section{References}

Afzal, A., Qayyum, M. A. \& Shah, M. H. 2019. Study of Trace Metal Imbalances in the Scalp Hair of Stomach Cancer Patients with Different Types and Stages. Biological trace element research, $1-10$.

Agriculture, F. M. O. 2012. Agreste. Recensement agricole 2010 [Online]. https://agreste.agriculture.gouv.fr/agreste-web/disar on/!searchurl/searchUiid/search/: French Ministry of Agriculture. Available: https://agreste.agriculture.gouv.fr/agreste-web/disaron/ !searchurl/searchUiid/search/ [Accessed 05/2021 2021].

ANSES 2019. Avis de l'Agence nationale de sécurité sanitaire de l'alimentation, de l'environnement et du travail relatif à l'actualisation des indicateurs de risque alimentaire lié aux résidus de pesticides.

Appenzeller, B. M. R. 2015. Hair Analysis for the Biomonitoring of Human Exposure to Organic Pollutants. In: Kintz, P., Salomone, A. \& Vincenti, M. (eds.) Hair Analysis in Clinical and Forensic Toxicology. Elsevier Academic Press.

Appenzeller BMR, Tsatsakis AM (2012) Hair analysis for biomonitoring of environmental and occupational exposure to organic pollutants: State of the art, critical review and future needs. Toxicol Lett 210:119-140
AQICN, A. P. R.-T. A. Q. I. A. 2020. Air Pollution: Real-time Air Quality Index (AQI) [Online]. https://aqicn.org/: https://aqicn.org/. Available: https://aqicn.org/ [Accessed 11/07 2020].

Ballesteros MTL, Serrano IN, Álvarez SI (2017) Reference levels of trace elements in hair samples from children and adolescents in Madrid, Spain. J Trace Elem Med Biol 43:113-120

Behrooz RD, Barghi M, Bahramifar N, Esmaili-Sari A (2012) Organochlorine contaminants in the hair of Iranian pregnant women. Chemosphere 86:235-241

Beranger R, Hardy EM, Binter AC, Charles MA, Zaros C, Appenzeller BMR, Chevrier C (2020) Multiple pesticides in mothers' hair samples and children's measurements at birth: Results from the French national birth cohort (ELFE). Int J Hyg Environ Health 223:22-33

Beranger R, Hardy EM, Dexet C, Guldner L, Zaros C, Nougadere A, Metten MA, Chevrier C, Appenzeller BMR (2018) Multiple pesticide analysis in hair samples of pregnant French women: Results from the ELFE national birth cohort. Environ Int 120:43-53

Braun JM, Gennings C, Hauser R, Webster TFJE (2016) What can epidemiological studies tell us about the impact of chemical mixtures on human health? Environ Health Perspect 124:6-9

Carlin DJ, Rider CV, Woychik R, Birnbaum LS (2013) Unraveling the Health Effects of Environmental Mixtures: An NIEHS Priority. Environ Health Perspect 121:A6-A8

CEN, E. C. F. S. 2019. https://standards.cen.eu/index.html. Available: https://standards.cen.eu/index.html [Accessed 2019].

Christen V, Crettaz P, Fent K (2014) Additive and synergistic antiandrogenic activities of mixtures of azol fungicides and vinclozolin. Toxicol Appl Pharmacol 279:455-466

Covaci A, Hura C, Gheorghe A, Neels H, Dirtu AC (2008) Organochlorine contaminants in hair of adolescents from Iassy, Romania. Chemosphere 72:16-20

Docea AO, Goumenou M, Calina D, Arsene AL, Dragoi CM, Gofita E, Pisoschi CG, Zlatian O, Stivaktakis PD, Nikolouzakis TKJTL (2019) Adverse and hormetic effects in rats exposed for 12 months to low dose mixture of 13 chemicals: RLRS part III. Toxicol Lett 310:70-91

Dongarrà G, Varrica D, Tamburo E, D'andrea D (2012) Trace elements in scalp hair of children living in differing environmental contexts in Sicily (Italy). Environ Toxicol Pharmacol 34:160-169

Duca RC, Hardy E, Salquebre G, Appenzeller BMR (2014) Hair decontamination procedure prior to multi-class pesticide analysis. Drug Test Anal 6:55-66

Fays F, Hardy EM, Palazzi P, Haan S, Beausoleil C, Appenzeller BMR (2021) Biomonitoring of fast-elimination endocrine disruptors - results from a 6-month follow up on human volunteers with repeated urine and hair collection. Sci Total Environ 778:146330

Fillol C, Garnier R, Mullot J-U, Boudet C, Momas I, Salmi LR, Vandentorren SJB (2014) Prioritization of the biomarkers to be analyzed in the French biomonitoring program. Biomonitoring. https://doi.org/10.2478/bimo-2014-0010

Geyer HJ, Rimkus GG, Scheunert I, Kaune A, Schramm K-W, Kettrup A, Zeeman M, Muir DC, Hansen LG, Mackay D (2000) Bioaccumulation and occurrence of endocrine-disrupting chemicals (EDCs), persistent organic pollutants (POPs), and other organic compounds in fish and other organisms including humans. Springer, Bioaccumulation-New Aspects and Developments

Gil F, Hernández AF, Márquez C, Femia P, Olmedo P, López-Guarnido O, Pla A (2011) Biomonitorization of cadmium, chromium, manganese, nickel and lead in whole blood, urine, axillary hair and saliva in an occupationally exposed population. Sci Total Environ 409:1172-1180

Global Alliance on Health and Pollution, G. 2019. Pollution and Health Metrics. Global, Regional, and Country Analysis. December 2019. https://gahp.net/wp-content/uploads/2019/12/Pollutiona 
ndHealthMetrics-final-12_18_2019.pdf: Global Alliance on Health and Pollution, GAHP.

Goullé J-P, Mahieu L, Castermant J, Neveu N, Bonneau L, Lainé G, Bouige D, Lacroix C (2005) Metal and metalloid multi-elementary ICP-MS validation in whole blood, plasma, urine and hair: Reference values. Forensic Sci Int 153:39-44

Griffiths M, Payne PR, Stunkard AJ, Rivers JPW, Cox W (1990) Metabolic rate and physical development in children at risk of obesity. Lancet 336:76-78

Grova N, Salquèbre G, Appenzeller BMJA, Chemistry B (2013) Gas chromatography-tandem mass spectrometry analysis of 52 monohydroxylated metabolites of polycyclic aromatic hydrocarbons in hairs of rats after controlled exposure. Anal Bioanal Chem 405:8897-8911

Haines DA, Saravanabhavan G, Werry K, Khoury C (2017) An overview of human biomonitoring of environmental chemicals in the Canadian Health Measures Survey: 2007-2019. Int J Hyg Environ Health 220:13-28

Hardy, E. M., Dereumeaux, C., Guldner, L., Briand, O., Vandentorren, S., Oleko, A., Zaros, C. \& Appenzeller, B. M. J. E. I. 2021. Hair versus urine for the biomonitoring of pesticide exposure: Results from a pilot cohort study on pregnant women. 152: 106481

Hardy EM, Duca RC, Salquebre G, Appenzeller BMR (2015) Multiresidue analysis of organic pollutants in hair and urine for matrices comparison. Forensic Sci Int 249:6-19

Hernández AF, Tsatsakis AMJF, Toxicology C (2017) Human Exposure to Chemical Mixtures: Challenges for the Integration of Toxicology with Epidemiology Data in Risk Assessment 103:188-193

Iglesias-González A, Hardy EM, Appenzeller BM (2020) Cumulative exposure to organic pollutants of French children assessed by hair analysis. Environ Int 134:105332

Katsikantami I, Tzatzarakis MN, Karzi V, Stavroulaki A, Xezonaki P, Vakonaki E, Alegakis AK, Sifakis S, Rizos AK, Tsatsakis AM (2020) Biomonitoring of bisphenols A and S and phthalate metabolites in hair from pregnant women in Crete. Sci Total Environ 712:135651

Kintz, P., Salomone, A. \& Vincenti, M. 2015. Hair analysis in clinical and forensic toxicology, Academic Press.

Kokkinaki A, Kokkinakis M, Kavvalakis MP, Tzatzarakis MN, Alegakis AK, Maravgakis G, Babatsikou F, Fragkiadakis GA, Tsatsakis AM (2014) Biomonitoring of dialkylphosphate metabolites (DAPs) in urine and hair samples of sprayers and rural residents of Crete, Greece. Environ Res 134:181-187

Kortenkamp A (2007) Ten years of mixing cocktails: a review of combination effects of endocrine-disrupting chemicals. Environ Health Perspect 115:98-105

Kortenkamp A (2014) Low dose mixture effects of endocrine disrupters and their implications for regulatory thresholds in chemical risk assessment. Curr Opin Pharmacol 19:105-111

Kostoff RN, Goumenou M, Tsatsakis A (2018) The role of toxic stimuli combinations in determining safe exposure limits. Elsevier

Landrigan PJ, Fuller R, Acosta NJ, Adeyi O, Arnold R, Baldé AB, Bertollini R, Bose-O'reilly S, Boufford JI, Breysse PNJTL (2018) The Lancet Commission on Pollution and Health 391:462-512

Lehmann E, Oltramare C, Dibié JJN, Konaté Y, de Alencastro LF (2018) Assessment of human exposure to pesticides by hair analysis: The case of vegetable-producing areas in Burkina Faso. Environ Int 111:317-331

Li Y, Yang L, Wang W, Li H, Lv J, Zou X (2011) Trace element concentrations in hair of healthy Chinese centenarians. Sci Tot Environ 409:1

Liang B, Liu X, Hou J, Liang G, Gong W, Xu D, Zhang L (2014) PCBs levels and indicator congeners in children's and adolescents' hair. Environ Pollut 185:10-15
Mairie de Grande-Synthe, V. D. G.-S. http://www.ville-grande-synthe. fr/: Mairie de Grande-Synthe. Available: http://www.ville-grandesynthe.fr/ [Accessed 02/2021 2021].

Molnar D, Schutz Y (1997) The effect of obesity, age, puberty and gender on resting metabolic rate in children and adolescents. Eur J Pediatr 156:376-381

Nakashima Y, Jones CE, Yamanobe W, Kajii Y (2014) Near-surface vertical profiles of urban roadside NOx and fine particles. Aerosol Air Qual Res 156:376-381

Nougadère A, Merlo M, Héraud F, Réty J, Truchot E, Vial G, Cravedi J-P, Leblanc J-CJFC (2014) How dietary risk assessment can guide risk management and food monitoring programmes: The approach and results of the French Observatory on Pesticide Residues (ANSES/ORP). Food Control 41:32-48

Orp, C. J. S. D. D. D. U., de Contamination des milieux et d'imprégnation de la population, anses 2010. Exposition de la population générale aux résidus de pesticides en France.

Orton F, Ermler S, Kugathas S, Rosivatz E, Scholze M, Kortenkamp A (2014) Mixture effects at very low doses with combinations of anti-androgenic pesticides, antioxidants, industrial pollutant and chemicals used in personal care products. Toxicol Appl Pharmacol 278:201-208

Palazzi P, Hardy EM, Appenzeller BM (2019) Biomonitoring of children exposure to urban pollution and environmental tobacco smoke with hair analysis-A pilot study on children living in Paris and Yeu Island, France. Sci Total Environ 665:864-872

Palazzi P, Mezzache S, Bourokba N, Hardy EM, Schritz A, Bastien P, Emond C (2018) Exposure to polycyclic aromatic hydrocarbons in women living in the Chinese cities of BaoDing and Dalian revealed by hair analysis. Environ Int 121:1341-1354

Pena-Fernandez A, Gonzalez-Munoz M, Lobo-Bedmar M (2014) "Reference values" of trace elements in the hair of a sample group of Spanish children (aged 6-9 years)-Are urban topsoils a source of contamination? Environ Toxicol Pharmacol 38:141-152

Peng F-J, Hardy EM, Mezzache S, Bourokba N, Palazzi P, Stojiljkovic N, Bastien P, Li J, Soeur J, Appenzeller BM (2020a) Exposure to multiclass pesticides among female adult population in two Chinese cities revealed by hair analysis. Environ Int 138:105633

Peng F, Hardy E, Béranger R, Mezzache S, Bourokba N, Bastien P, Li J, Zaros C, Chevrier C, Palazzi P, Soeur J, Appenzeller B (2020b) Human exposure to PCBs, PBDEs and bisphenols revealed by hair analysis: A comparison between two adult female populations in China and France. Environ Pollut 267:115425

Polledri E, Mercadante R, Nijssen R, Consonni D, Mol H, Fustinoni S (2019) Hair as a matrix to evaluate cumulative and aggregate exposure to pesticides in winegrowers. Sci Total Environ 687:808-816

Price K, Haddad S, Krishnan K (2003) Physiological modeling of agespecific changes in the pharmacokinetics of organic chemicals in children. J Toxicol Environ Health A 66:417-433

Protano C, Astolfi ML, Marconi E, Antonucci A, Canepari S, Piamonti D, Brunori M, Vitali M (2020) Occupational exposure assessment of major and trace elements in human scalp hair among a group of eritrean workers. Biol Trace Elem Res 197:89-100

Reis AP, Patinha C, Noack Y, Robert S, Dias AC (2014) Assessing human exposure to aluminium, chromium and vanadium through outdoor dust ingestion in the Bassin Minier de Provence, France. Environ Geochem Health 36:303-317

Rodrigues JL, Batista BL, Nunes JA, Passos CJS, Barbosa FJ (2008) Evaluation of the use of human hair for biomonitoring the deficiency of essential and exposure to toxic elements. Sci Tot Environ 405:370-376

Rowbotham AL, Levy LS, Shuker LK (2000) Chromium in the environment: an evaluation of exposure of the UK general population and possible adverse health effects. Journal of Toxicology and Environmental Health-Part B-Critical Reviews 3:145-178 
Sarigiannis DA, Hansen UJEH (2012) Considering the cumulative risk of mixtures of chemicals-a challenge for policy makers. Environ Health 11:1-12

Schummer C, Salquèbre G, Briand O, Millet M, Appenzeller BM (2012) Determination of farm workers' exposure to pesticides by hair analysis. Toxicol Lett 210:203-210

Senofonte O, Violante N, Caroli S (2000) Assessment of reference values for elements in human hair of urban schoolboys. J Trace Elem Med Biol 14:6-13

Shah F, Kazi TG, Afridi HI, Khan S, Kolachi NF, Arain MB, Baig JA (2011) The influence of environmental exposure on lead concentrations in scalp hair of children in Pakistan. Ecotox Environ Safe 74:727-732

Shukla S, Jhamtani RC, Dahiya M, Agarwal R (2017) Oxidative injury caused by individual and combined exposure of neonicotinoid, organophosphate and herbicide in zebrafish. Toxicol Rep $4: 240-244$

Silva E, Rajapakse N, Kortenkamp A (2002) Something from "nothing"- eight weak estrogenic chemicals combined at concentrations below NOECs produce significant mixture effects. Environ Sci Technol 36:1751-1756

Skalny AV, Mazaletskaya AL, Ajsuvakova OP, Bjørklund G, Skalnaya MG, Notova SV, Chernova LN, Skalny AA, Burtseva TI, Tinkov AA (2020) Hair trace element concentrations in autism spectrum disorder (ASD) and attention deficit/hyperactivity disorder (ADHD). J Trace Elements Med Biol 61:126539

Skalny AV, Skalnaya MG, Grabeklis AR, Zhegalova IV, Serebryansky EP, Demidov VA, Salnikova EV, Uzhentseva MS, Lobanova YN, Skalny AA (2018) Interactive effects of age and gender on levels of toxic and potentially toxic metals in children hair in different urban environments. Int J Environ Anal Chem 98:520-535

Song Q, Zheng P, Qiu L, Jiang X, Zhao H, Zhou H, Han Q, Diao X (2016) Toxic effects of male Perna viridis gonad exposed to BaP, DDT and their mixture: a metabolomic and proteomic study of the underlying mechanism. Toxicol Lett 240:185-195

Starr JM, Scollon EJ, Hughes MF, Ross DG, Graham SE, Crofton KM, Wolansky MJ, Devito MJ, Tornero-Velez R (2012) Environmentally relevant mixtures in cumulative assessments: an acute study of toxicokinetics and effects on motor activity in rats exposed to a mixture of pyrethroids. Toxicol Sci 130:309-318

Tao S, Wang Y, Wu S, Liu S, Dou H, Liu Y, Lang C, Hu F, Xing B (2007) Vertical distribution of polycyclic aromatic hydrocarbons in atmospheric boundary layer of Beijing in winter. Atmos Environ 41:9594-9602

Tsatsakis A, Kouretas D, Tzatzarakis M, Stivaktakis P, Tsarouhas K, Golokhvast K, Rakitskii V, Tutelyan V, Hernandez A, Rezaee RJH, Toxicology E (2017) Simulating Real-Life Exposures to Uncover Possible Risks to Human Health: a Proposed Consensus for a Novel Methodological Approach 36:554-564

Tsatsakis A, Tzatzarakis M, Tutudaki M (2008a) Pesticide levels in head hair samples of Cretan population as an indicator of present and past exposure. Forensic Sci Int 176:67-71

Tsatsakis A, Tzatzarakis M, Tutudaki M, Babatsikou F, Alegakis A, Koutis C (2008b) Assessment of levels of organochlorine pesticides and their metabolites in the hair of a Greek rural human population. Hum Exp Toxicol 27:933-940

Tzatzarakis MN, Barbounis EG, Kavvalakis MP, Vakonaki E, Renieri E, Vardavas AI, Tsatsakis AM (2014) Rapid method for the simultaneous determination of DDTs and PCBs in hair of children by headspace solid phase microextraction and gas chromatographymass spectrometry (HSSPME/GC-MS). Drug Test Anal 6:85-92

Vandenberg LN, Hauser R, Marcus M, Olea N, Welshons WV (2007) Human exposure to bisphenol A (BPA). Reprod Toxicol 24:139-177

Vorkamp K, Castano A, Antignac JP, Boada LD, Cequier E, Covaci A, Lopez ME, Haug LS, Kasper-Sonnenberg M, Koch HM, Luzardo OP, Osite A, Rambaud L, Pinorini MT, Sabbioni G, Thomsen C (2021) Biomarkers, matrices and analytical methods targeting human exposure to chemicals selected for a European human biomonitoring initiative. Environ Int 146:20

Wang B, Li Z, Ma Y, Qiu X, Ren A (2016) Association of polycyclic aromatic hydrocarbons in housewives' hair with hypertension. Chemosphere 153:315-321

Wang W, Wu F, Zheng J, Wong MH (2013) Risk assessments of PAHs and $\mathrm{Hg}$ exposure via settled house dust and street dust, linking with their correlations in human hair. J Hazard Mater 263:627-637

Wild CP (2012) The exposome: from concept to utility. Int J Epidemiol 41:24-32

World Health Organization, W. 2020. Air Pollution [Online]. https:// gahp.net/wp-content/uploads/2019/12/PollutionandHealthMe trics-final-12_18_2019.pdf: WHO. Available: https://gahp.net/ wp-content/uploads/2019/12/PollutionandHealthMetrics-final12_18_2019.pdf [Accessed 05/2021 2021].

Wu L-H, Zhang X-M, Wang F, Gao C-J, Chen D, Palumbo JR, Guo Y, Zeng EY (2018) Occurrence of bisphenol $\mathrm{S}$ in the environment and implications for human exposure: a short review. Sci Total Environ 615:87-98

Yamamoto Y, Ishizaki A, Kataoka H (2015) Biomonitoring method for the determination of polycyclic aromatic hydrocarbons in hair by online in-tube solid-phase microextraction coupled with high performance liquid chromatography and fluorescence detection. J Chromatogr B 1000:187-191

Žalmanová T, Hošková K, Nevoral J, Prokešová Š, Zámostná K, Kott T, Petr J (2016) Bisphenol S instead of bisphenol A: a story of reproductive disruption by regretable substitution-a review. Czeh J Anim Sci 61:433-449

Zheng J, Yu L-H, Chen S-J, Hu G-C, Chen K-H, Yan X, Luo X-J, Zhang S, Yu Y-J, Yang Z-Y (2016) Polychlorinated biphenyls $(\mathrm{PCBs})$ in human hair and serum from e-waste recycling workers in southern China: Concentrations, chiral signatures, correlations, and source identification. Environ Sci Technol 50:1579-1586

Publisher's Note Springer Nature remains neutral with regard to jurisdictional claims in published maps and institutional affiliations. 